\title{
Soft-Photoconversion Using Floating Self-Assembled Crystalline Films of Porphyrin Nanostructures
}

\author{
Andrés F. Molina-Osorio, David Cheung, Colm O'Dwyer, Andrew A. Stewart, Manuel Dossot, Grégoire \\ Herzog, Micheal D. Scanlon
}

Submitted date: 27/07/2019 - Posted date: 29/07/2019

Licence: CC BY-NC-ND 4.0

Citation information: Molina-Osorio, Andrés F.; Cheung, David; O'Dwyer, Colm; Stewart, Andrew A.; Dossot, Manuel; Herzog, Grégoire; et al. (2019): Soft-Photoconversion Using Floating Self-Assembled Crystalline Films of Porphyrin Nanostructures. ChemRxiv. Preprint.

One of many evolved functions of biological cell membranes is to induce and regulate self-assembly of photoactive molecules into efficient light harvesting nanomaterials. Synthetic molecular assemblies at soft interfaces exhibit macroscale long-range order and so provide routes to biomimetic analogues that minimise concentration quenching. Here, we report the facile assembly of free-standing layered crystalline films of zinc(II) meso-tetrakis(4-carboxyphenyl)porphyrin nanostructures that exhibit significant photocurrents in situ at an electrified liquid | liquid interface. This methodology does not require acidic conditions, specialised amphiphilic porphyrins, or the use of additives or external stimuli. The assembly process is driven by an interplay between the hydrophobicity gradient at an immiscible aqueous | organic interface and optimised hydrogen bonding in the formed nanostructure. Highly-ordered interfacial nanostructures may provide a new paradigm for realisation of light-harvesting antennae in artificial photosynthetic technologies.

File list (2) 


\section{Soft-photoconversion using floating self-assembled crystalline films of porphyrin nanostructures}

Andrés F. Molina-Osorio, ${ }^{1,2}$ David L. Cheung, ${ }^{3}$ Colm O’Dwyer, ${ }^{4,5,6}$ Andrew Stewart, ${ }^{2,7}$

Manuel Dossot, ${ }^{8}$ Grégoire Herzog, ${ }^{8}$ and Micheál D. Scanlon. ${ }^{1,2,9 *}$

${ }^{1}$ Department of Chemical Sciences, School of Natural Sciences, University of Limerick (UL), Limerick V94 T9PX, Ireland

${ }^{2}$ The Bernal Institute, University of Limerick (UL), Limerick V94 T9PX, Ireland

${ }^{3}$ School of Chemistry, National University of Ireland, Galway, University Road, Galway H91

TK33, Ireland

${ }^{4}$ School of Chemistry, University College Cork, Cork T12 YN60 Ireland

${ }^{5}$ Micro-Nano Systems Centre, Tyndall National Institute, Lee Maltings, Cork T12 R5CP, Ireland

${ }^{6}$ Environment Research Institute, University College Cork, Lee Road, Cork T23 XE10, Ireland

${ }^{7}$ Department of Physics, School of Natural Sciences, University of Limerick (UL), Limerick V94 T9PX, Ireland

${ }^{8}$ CNRS-Université de Lorraine, LCPME UMR 7564, 405 Rue de Vandoeuvre, 54600 Villerslès-Nancy, France

${ }^{9}$ The Advanced Materials and Bioengineering Research (AMBER) centre 


\section{Abstract}

One of many evolved functions of biological cell membranes is to induce and regulate selfassembly of photoactive molecules into efficient light harvesting nanomaterials. Synthetic molecular assemblies at soft interfaces exhibit macroscale long-range order and so provide routes to biomimetic analogues that minimise concentration quenching. Here, we report the facile assembly of free-standing layered crystalline films of zinc(II) meso-tetrakis(4carboxyphenyl)porphyrin nanostructures that exhibit significant photocurrents in situ at an electrified liquid | liquid interface. This methodology does not require acidic conditions, specialised amphiphilic porphyrins, or the use of additives or external stimuli. The assembly process is driven by an interplay between the hydrophobicity gradient at an immiscible aqueous | organic interface and optimised hydrogen bonding in the formed nanostructure. Highly-ordered interfacial nanostructures may provide a new paradigm for realisation of light-harvesting antennae in artificial photosynthetic technologies.

Photosynthetic organisms universally exploit antenna systems to capture high energy photons and funnel this excitation energy in the form of excitons toward a coupled reaction centre. ${ }^{1,2}$ There, the excitation energy is transformed into chemical potential in the form of a charge separated state. ${ }^{1,2}$ Self-assembled molecular antennae consisting of multi-layers of chromophores, such as porphyrins, can potentially function as high efficiency light harvesters due to their exceptionally high molar absorption coefficients $\left(10^{5} \mathrm{~cm}^{-1} \cdot \mathrm{M}^{-1}\right) .{ }^{3}$ However, to mimic the evolved nanomachinery in photoautotrophs and avoid "concentration quenching" of the excited state at disordered trap sites, ${ }^{3}$ the supramolecular packing of the individual chromophores within the antenna nanostructure must be precisely controlled and show longrange molecular order. 
Molecular self-assemblies at "soft" liquid | air or immiscible liquid | liquid interfaces can exhibit the required macroscale long-range order. ${ }^{4}$ These soft interfaces are exceptionally smooth, and have no inherent defects leading to an unrivalled macroscale uniformity in molecule-interface interactions. ${ }^{5,6}$ By contrast, the grain boundaries, step defects and edge sites always present at solid | liquid interfaces can impede diffusion of adsorbed molecules, trapping them in local energy minima as molecules stick to defect sites. ${ }^{7,8}$ The uniform templating of adsorbed molecules at liquid | air or immiscible liquid | liquid interfaces has been exploited to create a variety of ordered porphyrin nanostructures, ${ }^{9-14}$ yet a facile and robust route to create films of layered crystalline porphyrin nanostructures has not yet been reported to the best of our knowledge.

Here we describe light harvesting nanomaterials made using readily available, hydrophilic symmetrically substituted porphyrins that work efficiently in mild $\mathrm{pH}$ conditions. Thus, we avoid acidic conditions (that would lead to the expulsion of the central metal ion), ${ }^{15}$ as well as the use of synthetically challenging and relatively expensive amphiphilic porphyrin molecules, ${ }^{16}$ and more complicated routes using additives (e.g., divalent cations or surfactants) ${ }^{17-19}$ or external stimuli (e.g., electric fields). ${ }^{20-22}$ The key design criteria for the porphyrin molecule is that it must possess a meso-substituent capable of hydrogen bonding, and at $\mathrm{pH}=\mathrm{pKa}$ conditions either the protonated or deprotonated form of the porphyrin (each present in a 1:1 ratio) must have a molecular charge of zero and adsorb at the liquid | liquid interface.

We chose zinc(II) meso-tetrakis(4-carboxyphenyl)porphyrin (ZnTPPc) as a prototypical model system $\left(\mathrm{pKa}^{\mathrm{COOH}}=5.8\right)^{23}$ to demonstrate this new means of self-assembly at an immiscible aqueous | organic interface. Simply contacting aqueous ZnTPPc solutions prepared in citrate buffer at $\mathrm{pH} 5.8$ with a neat, immiscible organic phase of $\alpha, \alpha, \alpha,-$ trifluorotoluene (TFT) lead to the immediate formation of free-standing films of porphyrin 
nanostructures. We rationalise our findings using atomistic computer simulations of the hydrophobicity gradient at the immiscible aqueous $\mid$ organic interface that show that the carboxylic acid-carboxylate hydrogen bonding in the formed nanostructure is maximised under the mild $\mathrm{pH}=\mathrm{pKa}^{\mathrm{COOH}}$ conditions. The presence of multi-layers with strong visible light absorption (due to the extended $\pi-\pi$ conjugated electronic structure in porphyrin assemblies), and the crystalline macroscale long-range molecular order in the porphyrin nanostructure, suggested these films as ideal light-harvesting antennae in artificial photosynthetic technologies. To confirm this, we employed these nanostructures in a photoinduced interfacial electron transfer (PIET) arrangement between electron donor and acceptor species confined to the organic and aqueous phases, respectively. The energy absorbed by the nanostructure was used to create a highly energetic excited state that mediated electron transfer between the donor and acceptor molecules. In situ photocurrent transient measurements at a controllably electrified and LED illuminated liquid | liquid interface were as high as $20 \mu \mathrm{A} \cdot \mathrm{cm}^{-2}$, one order of magnitude higher than in previous

studies. ${ }^{24}$ Our findings clearly demonstrate that the ordered three-dimensional spatial arrangement of the individual porphyrin molecules in the nanostructure diminishes concentration quenching.

\section{Results and discussion}

Triggering the formation of interfacial nanostructures. The selective formation of ZnTPPc nanostructures at the interface between water and TFT was observed upon contacting the ZnTPPc aqueous solution (at pH 5.8) with neat TFT. A yellow/green colour was observed at the water | TFT interface within minutes, easily distinguishable from the purple colour of the bulk ZnTPPc aqueous solution, and associated with the formation of porphyrin interfacial nanostructures (Por-INs) (Fig. 1a,b and Supplementary Fig. 1). Self- 
assembly was observed in a very narrow $\mathrm{pH}$ range around the $\mathrm{pKa}$ of the carboxylic substituents $\left(\mathrm{pKa}^{\mathrm{COOH}}=5.8\right) .{ }^{23}$ At this $\mathrm{pH}, \mathrm{ZnTPPc}$ in solution exists in a ratio of $1: 1$ between the fully protonated $\left(\mathrm{H}_{4}[\mathrm{ZnTPPc}]\right)$ and fully deprotonated ([ZnTPPc $\left.]^{4-}\right)$ species. Molecular dynamics (MD) computer simulations indicate that the hydrophobic, neutral $\mathrm{H}_{4}[\mathrm{ZnTPPc}]$ species accumulates either at the interface, or even on the oil side of the interface (Fig. 1c,d and Supplementary Fig. 2), driven by the hydrophobicity gradient at the immiscible liquid | liquid interface. This interfacial layer acts as a template structure for the hydrophilic, anionic $[\mathrm{ZnTPPc}]^{4-}$ species to adsorb via carboxylic acid-carboxylate hydrogen-bonding and $\pi-\pi$ interactions (Fig. 1c). In this manner, a highly crystalline film of ZnTPPc nanostructures, stabilised by hydrogen bonding and $\pi-\pi$ interactions, builds up layer-by-layer at the interface. Akin to the clathrate crystals of ZnTPPc developed by Goldberg and coworkers, ${ }^{25-29}$ the strength of each individual hydrogen bond or $\pi-\pi$ interaction may be insubstantial, but the cooperative effect allows the net enthalpies of these multivalent interactions to cumulatively rival the strength of a covalent bond and stabilise the Por-IN. Ex situ scanning electron microscopy (SEM) images revealed the thickness of the floating film of ZnPor-INs to be approximately $135( \pm 5) \mathrm{nm}$ (Fig. 1e). 

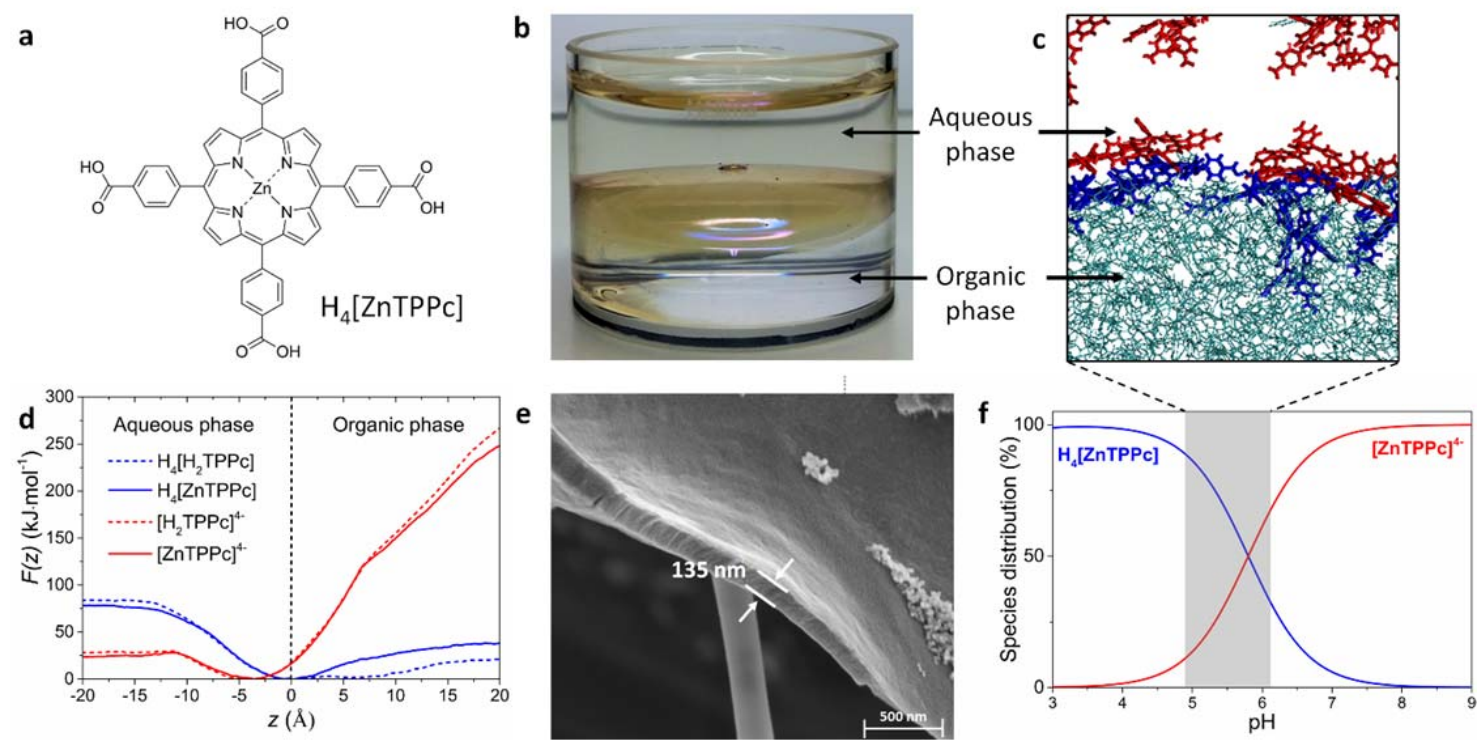

Fig. 1 | Mechanism of formation of the porphyrin interfacial nanostructures. a, Chemical structure of fully protonated zinc(II) meso-tetrakis(4-carboxyphenyl)porphyrin $\left(\mathrm{H}_{4}[\mathrm{ZnTPPc}]\right)$. b, Optical image of the robust adherence of the porphyrin interfacial nanostructures (Por-INs) to the interface after replacement of the buffer solution containing ZnTPPc with a buffer solution free of porphyrin. c, Representative computer structure of the water $\mid \alpha, \alpha, \alpha$,-trifluorotoluene (TFT) interface with $[\mathrm{ZnTPPc}]^{4-}$ (red) and $\mathrm{H}_{4}[\mathrm{ZnTPPc}]$ (dark blue) introduced from the aqueous phase (water molecules not shown for clarity, TFT molecules are cyan). d, Computed potential of mean force or free energy profiles for translation of ZnTPPc and $\mathrm{H}_{2}$ TPPc molecules across the water | TFT interface, averaged over $10 \mathrm{~ns}$ of free molecular dynamics, with the carboxylate groups on the 4-carboxyphenylsubstitutents either fully deprotonated, $[\mathrm{ZnTPPc}]^{4-}$ (solid red line) and $\left[\mathrm{H}_{2} \mathrm{TPPc}\right]^{4-}$ (dotted red line), or fully protonated, $\mathrm{H}_{4}[\mathrm{ZnTPPc}]$ (solid blue line) and $\mathrm{H}_{4}$ [ $\left.\mathrm{H}_{2} \mathrm{TPPc}\right]$ (dotted blue line). Water occupies the $\mathrm{z}<0$ region and TFT the $\mathrm{z}>0$ region. e, Scanning electron microscopy (SEM) image of a film of ZnPor-INs transferred from the water | TFT interface to a copper grid with a holey carbon substrate. f, Distribution percentage of neutral $\mathrm{H}_{4}$ [ZnTPPc] (blue line) and anionic $[\mathrm{ZnTPPc}]^{4-}$ (red line) in the aqueous phase as a function of $\mathrm{pH}$. The $\mathrm{pKa}$ of the carboxylate groups on the 4-carboxyphenyl-substitutents is $\mathrm{pH} \mathrm{5.8,} \mathrm{i.e.,} \mathrm{the} \mathrm{pH}$ yielding a 50/50 mixture of $\mathrm{H}_{4}[\mathrm{ZnTPPc}]$ and $[\mathrm{ZnTPPc}]^{4-}$.

Control experiments and MD simulations demonstrated that the ZnTPPc and free-base $\mathrm{H}_{2}$ TPPc molecules are kinetically stable in solution at $\mathrm{pH} 5.8$, and do not undergo spontaneous bulk aggregation in the concentration range studied (Supplementary Fig. 3). This indicates that the Por-INs form only by self-assembly in situ at the water | TFT interface.

Furthermore, to achieve selective Por-IN formation, the $\mathrm{pH}$ of the aqueous buffer solution must be controlled across a narrow $\mathrm{pH}$ range $5.1 \leq \mathrm{pH} \leq 6.1$ (Fig. 1f). More alkaline 
conditions inhibit formation of the Por-INs because of electrostatic repulsion between tetraanionic porphyrins. MD simulations show that the $[\mathrm{ZnTPPc}]^{4-}$ species prefer to sit in water at a distance of $\sim 3-5 \AA$ above the interface due to their hydrophilic nature (Fig. 1d). Meanwhile, at more acidic conditions, spectroscopic measurements reveal simultaneous formation of a host of randomly structured aggregates in the bulk aqueous phase (Supplementary Fig. 4). This $\mathrm{pH}$ dependency of Por-IN formation indicates that cooperative $\mathrm{H}$-bonding is prerequisite for self-assembly of an ordered film. Por-IN formation is not restricted to a single immiscible biphasic system, with control experiments showing that ZnPor-INs also form selectively at immiscible interfaces between water and 1,2-dichloroethane (DCE, Supplementary Fig. 5). TEM and XRD analysis confirm the crystalline and layered nature of the porphyrin interfacial nanostructures. Ex situ transmission electron microscopy (TEM) images with corresponding selected area electron diffraction (SAED) analysis, and X-ray diffraction (XRD) patterns from ZnPor-INs were acquired after immobilization of the film on an amorphous hydrophilized glass substrate (Fig 2a-d). The diffraction pattern for ZnPor-INs (Fig. 2d) bears a striking resemblance to NAFS (nanofilm on a solid surface) structural models for liquid phase interfacial synthesis of highly ordered molecular nanosheets. ${ }^{30}$ SAED and XRD estimate a $0.55-0.57 \mathrm{~nm}$ interplanar spacing between $\{110\}$ planes, with a $\sim 1.1 \mathrm{~nm}$ periodicity measured from HRTEM lattice fringes (Fig. 2a). The intense 220 reflection is consistent with a lack of layer-on-layer stacking order (due to non-registered stacking), but a highly crystalline nanosheet material is formed. The (200) reflections indicate strong axial coordination that is a distinct feature of layering along the $c$-axis normal to the support. Clearly discernible $(h k 0)$ reflections are consistent with a tetragonal unit cell with preferred growth orientation along the plane of the liquid | liquid interface (Fig. 2b,c).

Control experiments with $\mathrm{H}_{2}$ Por-INs demonstrate the key role of the central metal ion in enhancing the crystallinity of the film of porphyrin interfacial nanostructures. $\mathrm{H}_{2}$ Por-INs 
grown in the same way also form a crystalline 2D layered material, and show a similar XRD pattern but with a more pronounced amorphous background and suppressed reflection intensity compared to the ZnPor-INs (Fig. 2e). A schematic representation of the crystalline and interdigitated layered clathrate-type structure of the ZnPor-INs is illustrated in Fig. 2f, which assumes interdigitation to account for the reduced unit cell spacing compared to a NAFS-1 or NAFS-2 tetragonal metal-organic nanosheet crystalline structure.

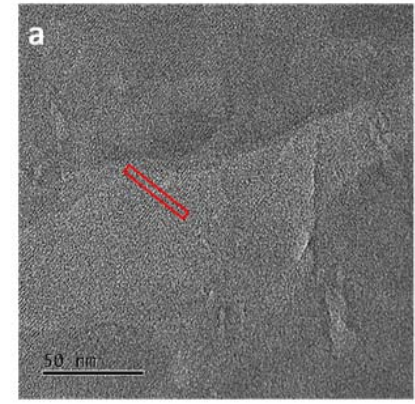

d

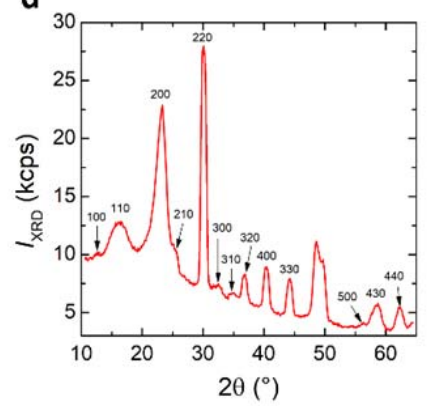

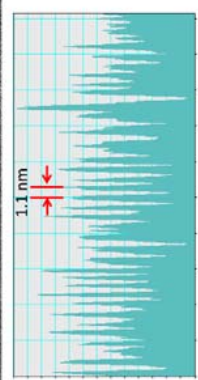

e

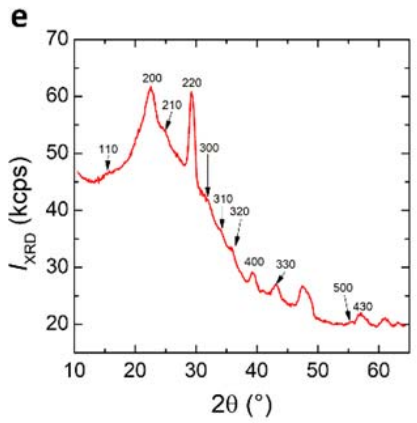

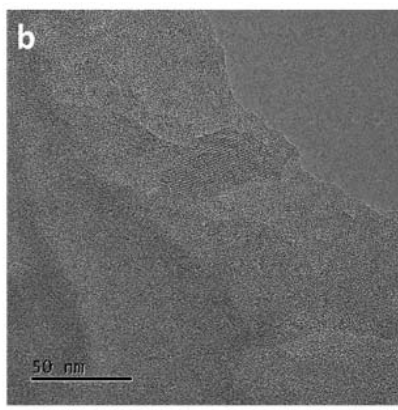

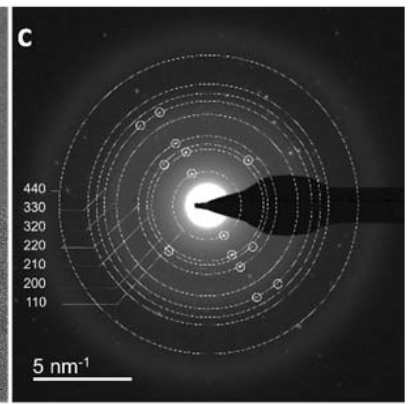

f

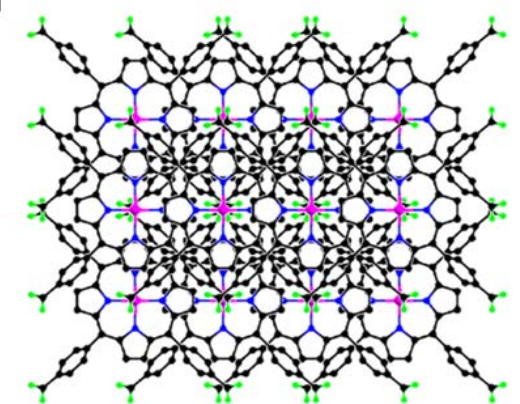

Fig. 2 | Characterisation of the ZnPor-INs and $\mathbf{H}_{2}$ Por-INs ex situ by transmission electron microscopy (TEM) and X-ray diffraction (XRD). (a) TEM image of the ZnPorINs transferred from the water | TFT interface to a copper grid with a holey carbon substrate, taken at $185 \mathrm{k}$ magnification. The profile of the lattice fringing shown on the right is taken from the area marked by the red box in the TEM image. (b) TEM image of ZnPor-INs, taken at $185 \mathrm{k}$ magnification at an accelerating voltage of $300 \mathrm{kV}$ and (c) the corresponding diffraction pattern with a $40 \mu \mathrm{m}$ selected area aperture and camera length of $580 \mathrm{~mm}$. (d) XRD pattern of the ZnPor-INs transferred to a silicon substrate. Patterns were acquired in $\omega$ $2 \theta$ geometry and clearly discernible $(h k 0)$ reflections confirms a tetragonal unit cell and dominant $c$-axis layering. (e) XRD of the $\mathrm{H}_{2}$ Por-INs. (f) Schematic representation of the crystalline and layered clathrate-type structure of the ZnPor-INs. Black balls represent carbon, pink is zinc, blue are nitrogen, and green are oxygen. 


\section{Adsorption isotherms indicate that assembly is driven by hydrogen-bonding and $\pi-\pi$ interactions between the tightly spaced porphyrins in the nanostructure. The interfacial}

concentration of porphyrin adsorbed to form the Por-INs was measured at equilibrium as a function of the solution concentration of ZnTPPc and $\mathrm{H}_{2}$ TPPc, respectively. Over the concentration range studied $(0.5-100 \mu \mathrm{M})$, ZnTPPc adsorption followed a Brunauer-EmmetTeller (BET) isotherm behaviour, whereas $\mathrm{H}_{2}$ TPPc adsorption followed a linear isotherm behaviour (Fig. 3). Using the BET model for liquid phase adsorption reported by Ebadi et al., ${ }^{31}$ the isotherm obtained for ZnTPPc adsorption was fit to Eqn. 1:

$\Gamma=\Gamma_{m} \frac{K_{1} C_{e q .}}{\left(1-K_{2} C_{e q .}\right)\left(1-K_{2} C_{e q .}+K_{1} C_{e q}\right)}$

in which $K_{1}$ and $K_{2}$ are the pseudo-equilibrium constants of adsorption to form the first and second layers of the ZnPor-INs, $\Gamma$ and $\Gamma_{m}$ are the equilibrium and monolayer porphyrin surface concentrations, respectively, and $C_{e q}$. is the equilibrium concentration of the porphyrin in solution. Non-linear fitting determined $\Gamma_{m}$ as $13.08( \pm 0.94) \mathrm{nmol} \cdot \mathrm{cm}^{-2}$, and $K_{1}$ and $K_{2}$ as $4.55 \times 10^{-2}( \pm 0.25)$ and $8.79 \times 10^{-3}\left( \pm 2.21 \times 10^{-4}\right) \mathrm{L} \cdot \mu$ moles, respectively $(95 \%$ confidence). Thus, the Gibbs free energy of adsorption $\left(\Delta G_{\text {ads. }}\right)$ of $\mathrm{ZnTPPc}$ to form the first and second layers of the ZnPor-INs are $7.65 \mathrm{~kJ} \cdot \mathrm{mol}^{-1}$ and $11.72 \mathrm{~kJ} \cdot \mathrm{mol}^{-1}$, respectively. These positive values of $\Delta G_{\text {ads. }}$ suggest that the packing interactions between individual neutral $\mathrm{H}_{4}[\mathrm{ZnTPP}]$ species and the organic phase are not sufficient to form thermodynamically favourable assemblies, that is, the entropic cost of assembly outweighs the small enthalpic gain in free solution. This suggests that the assembly observed experimentally (Fig. 1b) is mediated by trapping of the Por-INs at the interface and driven by hydrogen-bonding and $\pi-\pi$ interactions between the tightly spaced porphyrins in the nanostructure. 


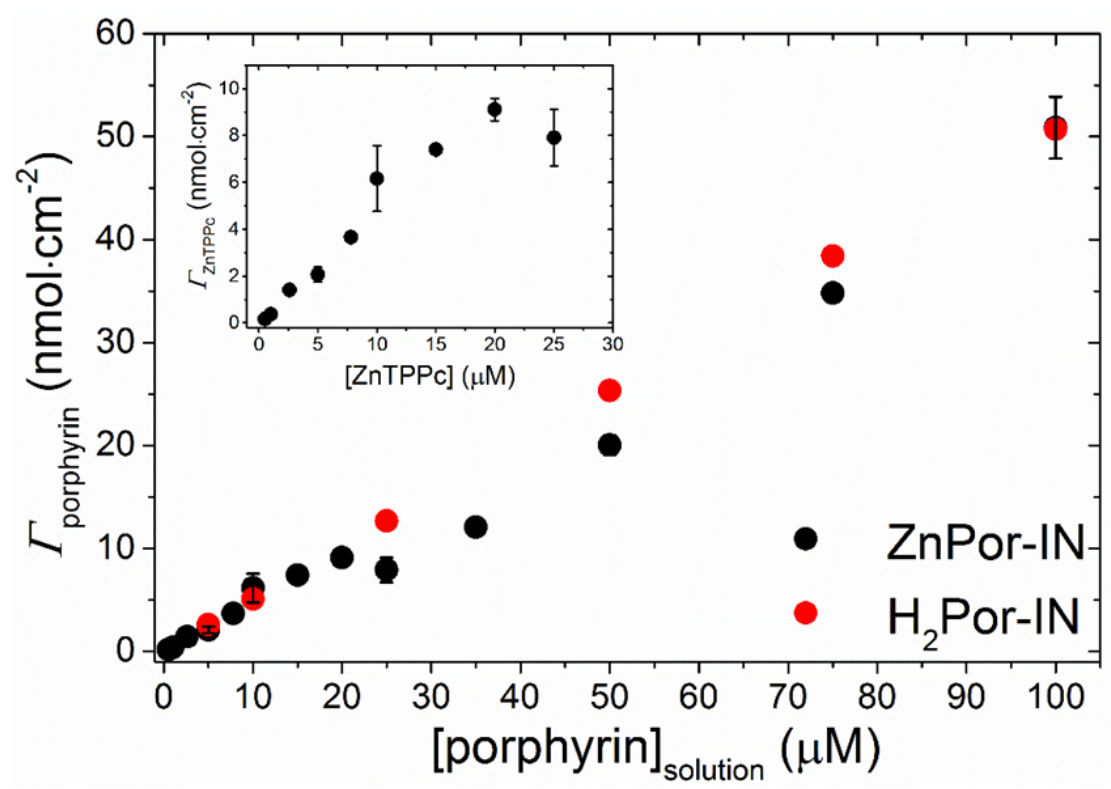

Fig. 3 | Adsorption isotherms obtained at $20{ }^{\circ} \mathrm{C}$ of $\mathrm{ZnTPPc}$ and $\mathrm{H}_{2} \mathrm{TPPc}$ at the water $\mid \mathrm{TFT}$ interface. Inset: Adsorption isotherm data for ZnTPPc at the water | TFT interface, highlighting the Brunauer-Emmet-Teller (BET) behavior.

The difference in the adsorption isotherms for $\mathrm{ZnTPPc}$ and $\mathrm{H}_{2} \mathrm{TPPc}$ further emphasises the influence of the metal centre during porphyrin interfacial adsorption. Previous studies at an aqueous | dodecane interface demonstrated that the adsorption of an oil-soluble metalloporphyrin was highly dependent on the nature of the central metal ion due to the different water coordination geometries around different metals. ${ }^{32}$ Thus, we used MD simulations to quantify the influence of the presence or absence of $\mathrm{Zn}^{2+}$, and the protonation state, on the adsorption of ZnTPPc and $\mathrm{H}_{2}$ TPPc at the water | TFT interface (Supplementary Fig. 6). For all model variants, the molecules were found to lie in the plane of the interface, with a dihedral angle between the porphyrin plane and the interface close to $0^{\circ}$ which suggests that the difference in the adsorption behaviour stems from different supramolecular packing modes within the Por-INs. Assuming perfectly flat lying molecules, the theoretical monolayer concentration of the ZnPor-INs was calculated as $3.18 \times 10^{14}$ molecules $\cdot \mathrm{cm}^{-2}$ (assuming the area of a single ZnTPPc molecule as $3.14 \mathrm{~nm}^{2}$, calculated from its molecular surface). Experimentally the value obtained from the ZnTPPc absorption isotherm is an order 
of magnitude greater at $4.76 \times 10^{15}$ molecules $\cdot \mathrm{cm}^{-2}$. Therefore, the experimental surface coverage suggests that the monolayer surface concentration $\left(\Gamma_{m}\right)$ corresponds to a layer of interdigitated molecules.

\section{Spectroscopic investigation of the effect of nanostructure formation on the electronic} structure of the interfacial porphyrins. Comparison of the in situ UV/vis absorption spectra of both ZnTPPc and $\mathrm{H}_{2}$ TPPc in solution with that of the corresponding Por-INs within the Soret band region are shown in Figs. 4a,b. The full spectra are shown in Supplementary Fig. 7 , with the absorption maxima $\left(\lambda_{\max }\right)$ of the Soret and Q bands summarised in Supplementary Table 1 . The $\lambda_{\max }$. value of the Soret band for the ZnPor-INs is slightly blue-shifted (422 to $413 \mathrm{~nm}$ ), while for the $\mathrm{H}_{2}$ Por-INs slightly red-shifted (414 to 419 $\mathrm{nm})$. Perturbation of the electronic absorption spectra in terms of shifts of the Soret and Q absorption bands, and spectral broadening of the Soret band, clearly indicate the presence of domains with slight variations in the geometric arrangements of the porphyrins within the nanostructure at the interface. Analogous to ZnTPPc in solution, the ZnPor-INs display two Q bands, indicating that the porphyrin ring remains metallated with $\mathrm{Zn}^{2+}$ upon nanostructure formation, and thus retains the $D_{4 \mathrm{~h}}$ symmetry typical of single ZnTPPc molecules. The $\mathrm{H}_{2}$ Por-INs display four Q bands, again indicating that the porphyrin ring retains the $D_{2 \mathrm{~h}}$ symmetry typical of single $\mathrm{H}_{2}$ TPPc molecules. In solution, one main peak centred at $422 \mathrm{~nm}$ was deconvoluted from the experimental spectrum of ZnTPPc (Fig. 4a). This peak represents the $\mathrm{B}(0,0)$ transition, indicating the monomeric nature of ZnTPPc under these experimental conditions. The latter is consistent with the adherence of ZnTPPc in solution to the BeerLambert law across an extensive concentration range (Supplementary Fig. 3), and with previous studies. ${ }^{33}$ Best fits in all other instances required multiple peaks, each related to different vibronic transitions, revealing the co-existence of monomers and dimers in solution 
for $\mathrm{H}_{2}$ TPPc (Fig. 4b) and domains with slight variations in the geometric arrangements of the porphyrins within the Por-INs.
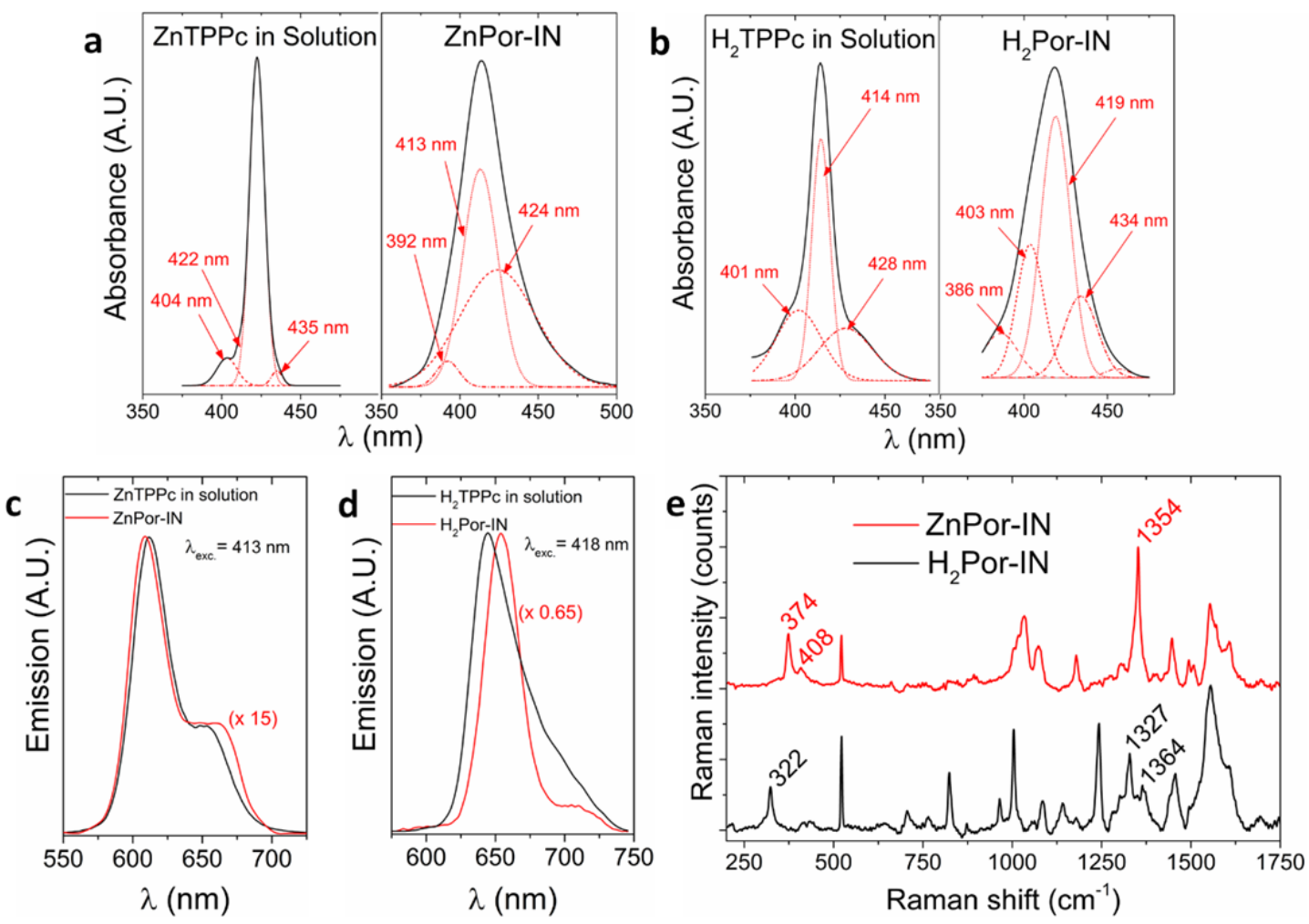

Fig. 4 | Spectroscopic characterisation of the ZnPor- and $\mathrm{H}_{2}$ Por-INs by in situ UV/vis absorbance and steady-state fluorescence, and ex situ Raman spectroscopy. Deconvolution of the Soret absorbance bands for a, ZnTPPc in solution and the ZnPor-INs and $\mathbf{b}, \mathrm{H}_{2}$ TPPc in solution and the $\mathrm{H}_{2}$ Por-INs. Comparison of the fluorescence emission spectra of $\mathbf{c}$, ZnTPPc in solution and the ZnPor-INs for an excitation wavelength $\left(\lambda_{\text {exc. }}\right)$ of $418 \mathrm{~nm}$ and d, $\mathrm{H}_{2}$ TPPc in solution and the $\mathrm{H}_{2}$ Por-INs for $\lambda_{\text {exc. }}$ of $413 \mathrm{~nm}$. e, Comparison of the Raman spectra of films of ZnPor- and the $\mathrm{H}_{2}$ Por-INs transferred from the water $\mid \mathrm{TFT}$ interface to a silicon substrate (see Supplementary Table 2 for peak assignments).

In situ steady-state fluorescence spectra were measured for a series of excitation wavelengths $\left(\lambda_{\text {exc. }}\right)$ spanning the Soret bands of both ZnTPPc and $\mathrm{H}_{2}$ TPPc in solution, and their corresponding Por-INs (Fig. 4c,d and Supplementary Figs. 8 and 9). Comparison of the emission profiles of ZnTPPc in solution and the ZnPor-INs shows that the $\mathrm{Q}(0,0)$ transient is slightly blue-shifted and $\mathrm{Q}(0,1)$ transition slightly red-shifted upon nanostructure formation 
(Fig. 4c). By contrast, the spectra of the $\mathrm{H}_{2}$ Por-INs were red-shifted in comparison to the spectra for $\mathrm{H}_{2}$ TPPc in solution, consisting of a peak at $654 \mathrm{~nm}$ and much less intense peak at $\sim 710 \mathrm{~nm}$ (Fig. 4d). The dependencies of the emission profiles on $\lambda_{\text {exc. }}$ across the Soret band mirrored the in situ UV/vis spectroscopy findings, confirming the monomeric or dimeric nature of the porphyrins in solution and presence of domains with slight variations in the geometric arrangements of the porphyrins within the Por-INs. Furthermore, the retention of fluorescence emission after nanostructure formation demonstrates how the crystalline longrange molecular order in the nanostructure leads to diminished concentration quenching, a key attribute when designing light-harvesting antennae in artificial photosynthetic technologies.

Since $\mathrm{ZnTPPc}$ self-assembles in mild $\mathrm{pH}$ conditions, expulsion of $\mathrm{Zn}^{2+}$ was avoided, as confirmed by analysis of the effect of nanostructure formation on the vibrational modes of the ZnPor- and $\mathrm{H}_{2}$ Por-INs by ex situ Raman spectroscopy (Fig. 4e). Prominent differences between the two are entirely consistent with previous comparisons of metallo- and free-base 4-carboxyphenyl-substituted porphyrin Raman spectra (see Supplementary table 2). ${ }^{34,35}$ The retention of $\mathrm{Zn}^{2+}$ increases the inter-system crossing (ISC) rate constant, $k_{\mathrm{ISC}}$, due to the heavy atom effect, increasing the probability of the forbidden $S_{1} \rightarrow T_{1}$ transition. From the $T_{1}$ state, relaxation may occur via phosphorescence or charge transfer. The long-lived (up to millisecond) excited triplet state lifetimes provides sufficient time for the excited state to efficiently interact with ground state quencher molecules, ${ }^{36}$ and is exploited herein to achieve photoconversion at a controllably electrified and LED illuminated liquid | liquid interface as described below.

\section{Enhancing photoconversion by an order-of-magnitude at electrified aqueous | organic} interfaces with floating ZnPor-INs. The concept of photo-induced interfacial electron transfer (PIET) mediated by ZnPor-INs between redox species chemically confined to 
different sides of a liquid | liquid interface is illustrated in Fig. 5a. The multi-layers of porphyrin in the ZnPor-INs floating at the interface function as high efficiency light harvesters. Upon illumination, the generated triplet excited state is reductively quenched by electron transfer from decamethylferrocene, and the ground state regenerated by hole transfer from $\mathrm{O}_{2}$. This charge separation is accompanied by an electrical photocurrent through an external circuit. Optimal functionalisation of the liquid | liquid interface with photoactive species is vital as PIET only involves those photosensitisers specifically adsorbed at the interface. Photocurrent transients associated with the rate of PIET were measured as 9 $\mu \mathrm{A} \cdot \mathrm{cm}^{-2}$ at $0 \mathrm{~V}$ and $20 \mu \mathrm{A} \cdot \mathrm{cm}^{-2}$ when the aqueous phase was polarised $0.5 \mathrm{~V}$ with respect to the organic phase. The magnitude of the photocurrents increase substantially at $0.5 \mathrm{~V}$ due to the increase in the rate of interfacial electron transfer and the suppression of shunt resistances associated with the competitive transfer of cationic by-products (decamethylferrocenium cations) across the interface. The photocurrents generated with the ZnPor-INs of $\sim 20 \mu \mathrm{A} \cdot \mathrm{cm}^{-}$ ${ }^{2}$ are an order of magnitude greater than those under similar conditions $\left(<1 \mu \mathrm{A} \cdot \mathrm{cm}^{-2}\right)$ with ZnTPPc molecules adsorbed at the interface. ${ }^{24,37}$ This step-change in photoconversion efficiency demonstrates the feasibility of using these highly ordered molecular assemblies in photosynthetic technologies. 
a
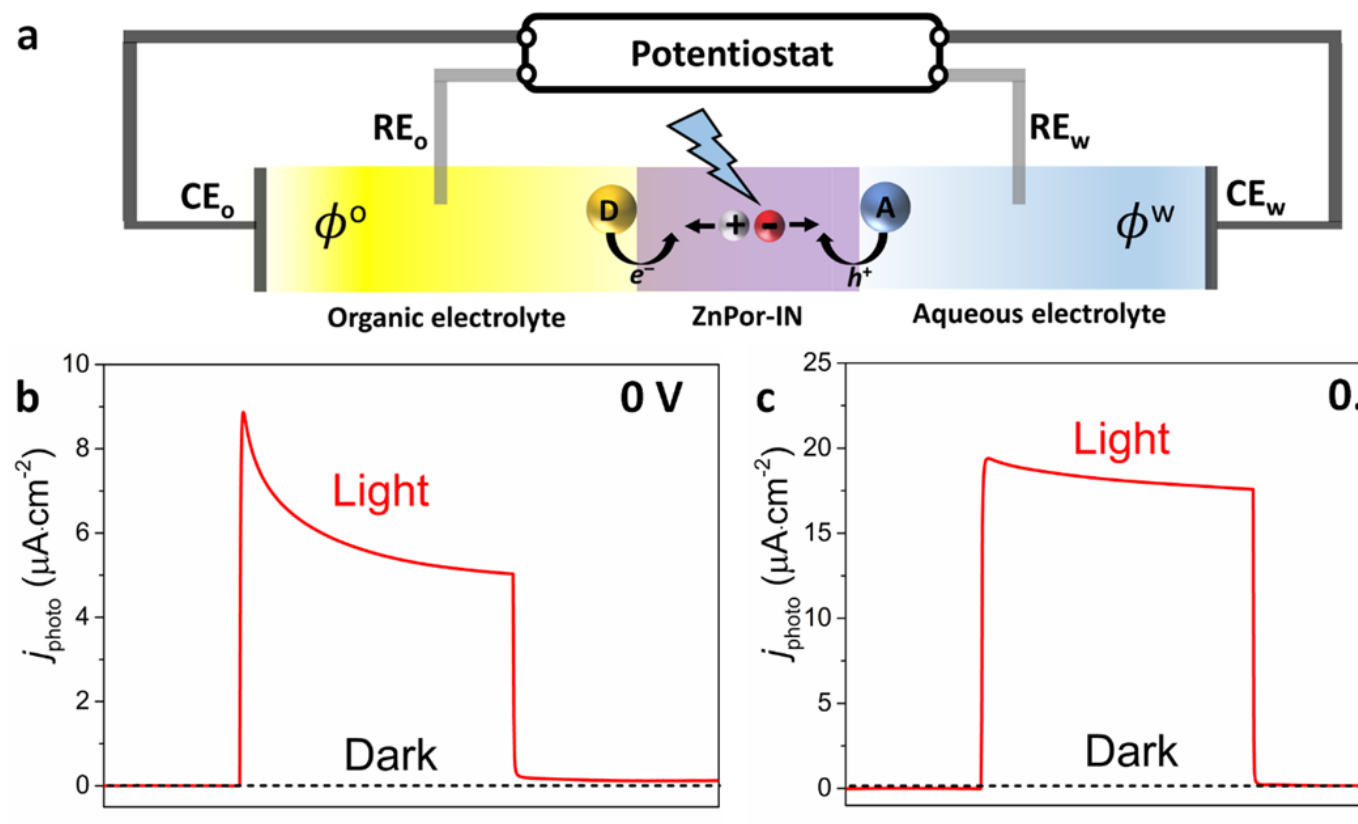

Time (s)

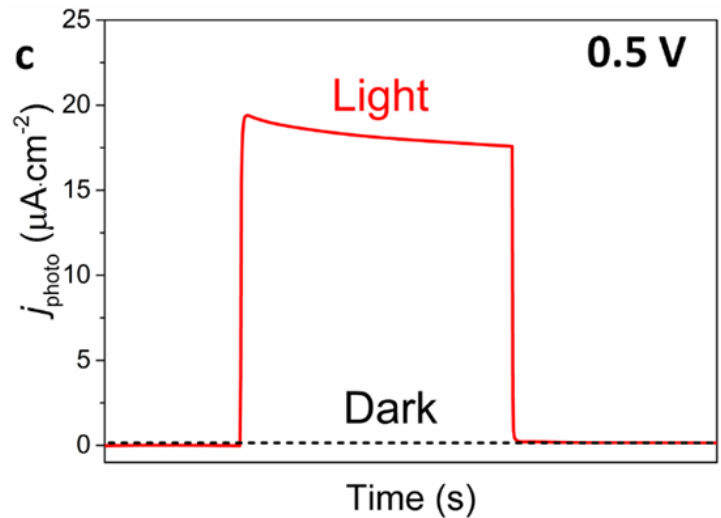

Fig. 5 | Soft-photoconversion at the interface between two immiscible liquids. a, Schematic of "soft-photoconversion"; converting light energy to chemical energy using dyesensitised electrified liquid | liquid interfaces. The donor species (D) is decamethylferrocene and the acceptor species (A) is $\mathrm{O}_{2}$. The ZnTPPc triplet excited state in the crystalline, layered ZnPor-INs undergoes reductive quenching by decamethylferrocene, with $\mathrm{O}_{2}$ regenerating the ground state. Thus, light energy is converted to chemical energy in the form of the oxidised donor $\left(\mathrm{D}^{+}\right)$and reduced acceptor $\left(\mathrm{A}^{-}\right)$spatially separated on either side of the water $\mid \mathrm{TFT}$ interface. Photocurrent transients were measured $\mathbf{b}$, at $0 \mathrm{~V}$ and $\mathbf{c}$, at a positive polarisation of the interface $(0.5 \mathrm{~V})$, at $\mathrm{pH} 5.8$ and $5 \mathrm{mM}$ decamethyferrocene in the TFT phase. The ZnPorINs floating at the water | TFT interface were illuminated with an LED (470 $\mathrm{nm}$ at 50 $\mathrm{mW} \cdot \mathrm{cm}^{-2}$ ) controlled by the potentiostat. The water $\mid$ TFT interface was electrified using a specialised 4-electrode electrochemical cell $\left(\mathrm{CE}_{\mathrm{w}}\right.$ and $\mathrm{CE}_{\mathrm{o}}$ are the counter electrodes in the water and TFT phases, respectively, and $\mathrm{RE}_{\mathrm{w}}$ and $\mathrm{RE}_{\mathrm{o}}$ are the reference electrodes in each phase).

\section{Conclusions}

The defect-free nature of the water | organic interface provides an ideal platform to selfassemble interfacial nanostructures with unique structural arrangements. In this Article, we report the self-assembly of free-floating interfacial nanostructures of zinc meso-tetrakis(4carboxyphenyl)porphyrin. The nanostructures are stabilised by cooperative hydrogen bonding and, due to the templating interaction of the interface with adsorbed porphyrin molecules, possess a crystalline, layered structure. This approach uniquely harnesses the difference in 
hydrophobicity between the neutral protonated and tetra-anionic non-protonated versions of the porphyrin at $\mathrm{pKa}$ conditions, combined with the introduction of a hydrophobicity gradient to trigger interfacial self-assembly. We open a new avenue to porphyrin nanostructure formation under mild experimental conditions without the need for acidic $\mathrm{pH}$, designer amphiphilic porphyrin molecules, aggregation-inducing additives or external triggers. The macroscale long-range molecular order and diminished concentration quenching of these photoactive nanostructures facilitates their application in next generation photocatalytic, photovoltaic, opto-electronic and sensor devices. In this regard, the feasibility of using such nanostructures for light collection and harvesting was demonstrated in situ by measuring photocurrents associated with photoinduced interfacial electron transfer across the water| TFT interface, with an order-of-magnitude increase in photoconversion efficiency achieved in comparison to previous studies. The ability to isolate the photoactive film at the liquidliquid interface provides an elegantly simple system for future exploration of photo-induced electron transfer at electrified soft interfaces to gain the fundamental insights necessary to realise a new approach to solar energy conversion entirely based on a self-assembled system.

\section{Experimental Methods}

Chemicals. All reagents were used as received without further purification. Meso-tetrakis(4carboxyphenyl)porphyrin $\left(\mathrm{H}_{2} \mathrm{TPPc}, \geq 98 \%\right.$ ) and its zinc(II) derivative (ZnTPPc, $\geq 98 \%$ ) were obtained from Porphychem. Lithium hydroxide ( $\mathrm{LiOH}, \geq 98 \%$ ), citric acid $\left(\mathrm{H}_{3} \mathrm{Cit}, \geq 99.5 \%\right.$ ), decamethylferrocene $(97 \%)$, and 1,2-dichloroethane (DCE, $\geq 99.0 \%$ ) were purchased from Sigma-Aldrich, and $\alpha, \alpha, \alpha$-trifluorotoluene (TFT, $\geq 99 \%$ ) from Acros Organics. All aqueous solutions were prepared using Milli-Q ${ }^{\circledR}$ deionized water (18.2 M $\Omega$ ). Aqueous solutions of ZnTPPc were prepared by directly dissolving the solid in the lithium citrate buffer preadjusted to the desired $\mathrm{pH}$, followed by sonication of the solution for three minutes. Initially, 
$\mathrm{H}_{2}$ TPPc was insoluble in the buffer at neutral $\mathrm{pH}$. Therefore, the solid was dissolved first in LiOH and the $\mathrm{pH}$ subsequently adjusted with $\mathrm{H}_{3} \mathrm{Cit}$. The ionic strength of each lithium citrate buffer solution containing either porphyrin was maintained at $10( \pm 2) \mathrm{mM}$.

Characterisation. The films of Por-INs were gently transferred to a silicon substrate for SEM, XRD and Raman characterisation, or an Agar Scientific TEM grid (Holey Carbon film 300 Mesh $\mathrm{Cu}$ ) for TEM imaging, by bringing the solid supports into contact with the interface. Prior to imaging, the samples were sequentially rinsed with water and TFT, and dried under a stream of nitrogen gas. TEM images were acquired on a Thermo Fisher double aberration corrected Titan Themis, spot size 6, on a Gatan Oneview detector. SEM images were obtained on a FEI Quanta 650 FEG high resolution SEM. X-ray diffraction patterns (XRD) were acquired in $\theta-2 \theta$ geometry with a Phillips Xpert PW3719 diffractometer using $\mathrm{Cu} \mathrm{K} \alpha$ radiation $(\lambda=0.15418 \mathrm{~nm}$, operation voltage $40 \mathrm{kV}$, current $40 \mathrm{~mA})$. Patterns were also acquired in $\omega-2 \theta$ geometry using a PANalytical X'pert PRO XRD. UV/vis absorbance spectra were collected in a Thermo Scientific Evolution 60S UV/vis spectrophotometer with illumination provided by a Xenon light source (accuracy $\pm 0.8 \mathrm{~nm}$ ). Steady-state fluorescence experiments were performed in a LS 55 Perkin Elmer Fluorescence spectrometer. The experimental configuration implemented to obtain UV/vis and steady-state fluorescence spectra of the Por-INs is illustrated in Supplementary Fig. 10. Raman measurements were carried out using a Horiba Jobin Yvon T64000 spectrometer equipped with a nitrogen cooled CCD detector. The laser wavelength was $532 \mathrm{~nm}$ with a power of $13 \mathrm{~mW}$. Raman spectra were obtained in 10 acquisitions of 30 seconds duration.

Adsorption isotherms. Vials containing biphasic systems of $\mathrm{ZnTPPc}$ or $\mathrm{H}_{2} \mathrm{TPPc}$ in lithium citrate buffer (10 mM ionic strength, $\mathrm{pH} 5.8)$ at different initial bulk concentrations and TFT as the organic phase were prepared and left to stand for 24 hours. After this time, the Por-INs formed and all remaining unadsorbed porphyrin in the bulk aqueous phase was extracted by 
thoroughly rinsing with porphyrin-free buffer solution. The solutions containing unadsorbed porphyrin were collected and analysed by UV/vis absorbance spectroscopy to quantify the porphyrin concentration therein (final bulk concentration). By subtracting the final from the initial bulk concentrations, the surface concentration (number of moles adsorbed per geometric area of aqueous | organic interface) was determined. All quantifications were performed using a calibration curve.

Molecular dynamics simulations. Simulations of interfacial adsorption and assembly were performed using a pre-equilibrated water | TFT interface, consisting water and TFT regions with 4000 water molecules and 1226 TFT molecules, respectively. Full details are provided in the Supplementary Information.

\section{Photocurrent transient measurements at an electrified aqueous $\mid$ organic interface.}

Photocurrent measurements with a DC illumination were performed using the LED driver provided by Metrohm Autolab in conjunction with a PGSTAT204 in a 4-electrode configuration as presented in Supplementary Fig. 11. The overlap of the emission spectrum of the LED with the absorption spectra of $\mathrm{ZnTPPc}, \mathrm{H}_{2}$ TPPc and their respective Por-INs is presented in Supplementary Fig. 12. The determination of the photon flux at the electrified liquid | liquid interface as a function of the LED driving current is outlined in Supplementary Fig. 13.

Data availability. The authors declare that all data supporting the findings of this study are available within the article and its Supplementary Information files and from the corresponding author upon request.

\section{References}

1. Scholes, G. D., Fleming, G. R., Olaya-Castro, A. \& Van Grondelle, R. Lessons from nature about solar light harvesting. Nat. Chem. 3, 763-774 (2011). 
2. Mirkovic, T. et al. Light absorption and energy transfer in the antenna complexes of photosynthetic organisms. Chem. Rev. 117, 249-293 (2017).

3. Otsuki, J. Supramolecular approach towards light-harvesting materials based on porphyrins and chlorophylls. J. Mater. Chem. A 6, 6710-6753 (2018).

4. Bigioni, T. P. et al. Kinetically driven self assembly of highly ordered nanoparticle monolayers. Nat. Mater. 5, 265-270 (2006).

5. Michael, D. \& Benjamin, I. Molecular dynamics simulation of the water|nitrobenzene interface. J. Electroanal. Chem. 450, 335-345 (1998).

6. Strutwolf, J. et al. Probing liquid|liquid interfaces using neutron reflection measurements and scanning electrochemical microscopy. J. Electroanal. Chem. 483, $163-173$ (2000).

7. Mendes, A. C., Baran, E. T., Reis, R. L. \& Azevedo, H. S. Self-assembly in nature: Using the principles of nature to create complex nanobiomaterials. WIREs Nanomed Nanobiotechnol 5, 582-612 (2013).

8. Grzybowski, B. A., Wilmer, C. E., Kim, J., Browne, K. P. \& Bishop, K. J. M. Selfassembly: from crystals to cells. Soft Matter 5, 1110-1128 (2009).

9. Rong, Y., Chen, P., Wang, D. \& Liu, M. Porphyrin assemblies through the air/water interface: Effect of hydrogen bond, thermal annealing, and amplification of supramolecular chirality. Langmuir 28, 6356-6363 (2012).

10. Ponce, C. P., Araghi, H. Y., Joshi, N. K., Steer, R. P. \& Paige, M. F. Spectroscopic and structural studies of a surface active porphyrin in solution and in Langmuir-Blodgett films. Langmuir 31, 13590-13599 (2015).

11. Babu, S. S. \& Bonifazi, D. Self-organization of polar porphyrinoids. Chempluschem 79, 895-906 (2014).

12. Numata, M., Kinoshita, D., Taniguchi, N., Tamiaki, H. \& Ohta, A. Self-assembly of 
amphiphilic molecules in droplet compartments: An approach toward discrete submicrometer-sized one-dimensional structures. Angew. Chemie - Int. Ed. 51, 1844 1848 (2012).

13. Xie, F., Zhuo, C., Hu, C. \& Liu, M. H. Evolution of nanoflowers and nanospheres of zinc bisporphyrinate tweezers at the air/water interface. Langmuir 33, 3694-3701 (2017).

14. Qiu, Y., Chen, P. \& Liu, M. Interfacial assemblies of atypical amphiphilic porphyrins: Hydrophobicity/hydrophilicity of substituents, annealing effects, and supramolecular chirality. Langmuir 26, 15272-15277 (2010).

15. Nagatani, H. \& Watarai, H. Direct spectrophotometric measurement of demetalation kinetics of 5,10,15,20-tetraphenylporphyrinatozinc(II) at the liquid-liquid interface by a centrifugal liquid membrane method. Anal. Chem. 70, 2860-2865 (1998).

16. Lin, L., Wang, T., Lu, Z., Liu, M. \& Guo, Y. In situ measurement of the supramolecular chirality in the langmuir monolayers of achiral porphyrins at the air/aqueous interface by second harmonic generation linear dichroism. J. Phys. Chem. C 118, 6726-6733 (2014).

17. Qian, D. J., Nakamura, C. \& Miyake, J. Multiporphyrin array from interfacial metalmediated assembly and its Langmuir-Blodgett films. Langmuir 16, 9615-9619 (2000).

18. Cheung, D. L. \& Carbone, P. How stable are amphiphilic dendrimers at the liquidliquid interface? Soft Matter 9, 6841-6850 (2013).

19. Guo, P. et al. Porphyrin nanoassemblies via surfactant-assisted assembly and single nanofiber nanoelectronic sensors for high-performance $\mathrm{H} 2 \mathrm{O} 2$ vapor sensing. ACS Nano 8, 3402-3411 (2014).

20. Nagatani, H., Samec, Z., Brevet, P.-F., Fermín, D. J. \& Girault, H. H. Adsorption and aggregation of meso-tetrakis(4-carboxyphenyl)porphyrinato Zinc(II) at the polarized 
water|1,2-dichloroethane interface. J. Phys. Chem. B 107, 786-790 (2003).

21. Yamamoto, S., Nagatani, H. \& Imura, H. Potential-induced aggregation of anionic porphyrins at liquid|liquid interfaces. Langmuir 33, 10134-10142 (2017).

22. Yamamoto, S., Nagatani, H., Morita, K. \& Imura, H. Potential-dependent adsorption and orientation of meso- substituted porphyrins at liquid|liquid interfaces studied by polarization-modulation total internal reflection fluorescence spectroscopy. J. Phys. Chem. C 120, 7248-7255 (2016).

23. Maiti, N. C., Mazumdar, S. \& Periasamy, N. J- and H-aggregates of porphyrin-surfactant complexes: Time-resolved fluorescence and other spectroscopic studies. J. Phys. Chem. B 102, 1528-1538 (1998).

24. Fermín, D. J., Ding, Z., Duong, H. D., Brevet, P.-F. \& Girault, H. H. Photoinduced electron transfer at liquid/liquid Interfaces. 1. Photocurrent measurements associated with heterogeneous quenching of zinc porphyrins. J. Phys. Chem. B 102, 10334-10341 (1998).

25. Diskin-Posner, Y. \& Goldberg, I. From porphyrin sponges to porphyrin sieves: a unique crystalline lattice of aquazinc tetra(4-carboxyphenyl)porphyrin with nanosized channels. Chem. Commun. 1961-1962 (1999). doi:10.1039/a906085e

26. Diskin-Posner, Y., Patra, G. K. \& Goldberg, I. Crystal engineering of 2-D and 3-D multiporphyrin architectures - The versatile topologies of tetracarboxyphenylporphyrin-based materials. Eur. J. Inorg. Chem. 2001, 2515-2523 (2001).

27. Diskin-Posner, Y., Dahal, S. \& Goldberg, I. New effective synthons for supramolecular self-assembly of meso-carboxyphenylporphyrins. Chem. Commun. 585-586 (2000). doi:10.1039/b001189o

28. George, S. \& Goldberg, I. Self-assembly of supramolecular porphyrin arrays by 
hydrogen bonding: New structures and reflections. Cryst. Growth Des. 6, 755-762 (2006).

29. Goldberg, I. Crystal Engineering of Metalloporphyrin Molecular Sieves and Zeolite Analogues. Acta Crystallogr. Sect. A Found. Crystallogr. 56, s122-s122 (2000).

30. Motoyama, S., Makiura, R., Sakata, O. \& Kitagawa, H. Highly crystalline nanofilm by layering of porphyrin metal-organic framework sheets. J. Am. Chem. Soc. 133, 5640 $5643(2011)$.

31. Ebadi, A., Soltan Mohammadzadeh, J. S. \& Khudiev, A. What is the correct form of BET isotherm for modeling liquid phase adsorption? Adsorption 15, 65-73 (2009).

32. Nagatani, H. \& Watarai, H. Specific adsorption of metal complexes of tetraphenylporphyrin at dodecane-water interface. Chem. Lett. 26, 167-168 (1997).

33. Pasternack, R. F., Francesconi, L., Raff, D. \& Spiro, E. Aggregation of nickel(II), copper(II), and zinc(II) derivatives of water-soluble porphyrins. Inorg. Chem. 12, 2606-2611 (1973).

34. Vlčková, B. et al. Surface-enhanced resonance Raman spectra of free base 5,10,15,20tetrakis(4-carboxyphenyl)porphyrin and its silver complex in systems with silver colloid: Direct adsorption in comparison to adsorption via molecular spacer. J. Phys. Chem. 97, 9719-9729 (1993).

35. Cotton, T. M., Schultz, S. G. \& Van Duyne, R. P. Surface-enhanced resonance raman scattering from water-soluble porphyrins adsorbed on a silver electrode. J. Am. Chem. Soc. 104, 6528-6532 (1982).

36. Fermín, D. J. \& Eugster, N. Organisation And Photoelectrochemical Reactivity of Water-Soluble Metalloporphyrins at the Liquid/Liquid Interface. in N4-Macrocyclic Metal Complexes (eds. Zagal, J. H., Bedioui, F. \& Dodelet, J.-P.) 517-574 (Springer Science+Business Media, Inc., 2006). 
37. Girault, H. H., Ding, Z., Brevet, O., Dung Duong, H. \& Fermín, D. J. Photoinduced electron transfer at liquid/liquid interfaces Part II. A study of the electron transfer and recombination dynamics by intensity modulated photocurrent spectroscopy (IMPS). Phys. Chem. Chem. Phys. 1, 1461-1467 (2002).

\section{Acknowledgements}

This publication has emanated from research by M.D.S. and A.F.M.-O. supported by the European Research Council through a Starting Grant (agreement no. 716792) and in part by a research grant from Science Foundation Ireland (SFI) (grant number 13/SIRG/2137). M.D.S. and A.F.M.-O. acknowledge funding through Irish Research Council New Foundations Awards (2014 and 2015) to facilitate the research. A.M.O., M.D.S., G.H. and M.D. are grateful to the support of the Irish Research Council and Campus France for travel support between the French and Irish groups through their joint ULYSSES programme. G. H. is grateful to the French Programme Investissement d'Avenir (PIA) “Lorraine Université d'Excellence" (Reference No. ANR-15-IDEX-04-LUE) for the partial financial support of this work. C.O.D. acknowledges support from Science Foundation Ireland (SFI) under Grant Numbers 13/TIDA/E2761, 14/IA/2581 and 15/TIDA/2893. Computational facilities and support for the molecular dynamics simulations were provided by the Irish Centre for HighEnd Computing (ICHEC).

\section{Author information}

\section{Contributions}

A.F.M.-O. and M.D.S. conceived and designed the experiments. D.L.C. performed and analysed the molecular dynamics computer simulations. C.O.D. acquired and processed the X-ray diffraction data. A.S. acquired and analysed the high-resolution TEM and SAED experiments. G.H. and M.D. acquired and analysed the steady-state fluorescence and Raman 
characterizations. A.F.M-O. and M.D.S. wrote the manuscript and all authors commented on the manuscript.

\section{Competing interests}

The authors declare no competing interests.

\section{Corresponding author}

Correspondence to Micheál D. Scanlon 


\section{Soft-photoconversion using floating self-assembled crystalline films of porphyrin nanostructures}

Andrés F. Molina-Osorio, ${ }^{1,2}$ David L. Cheung, ${ }^{3}$ Colm O’Dwyer, ${ }^{4,5,6}$ Andrew Stewart, ${ }^{2,7}$ Manuel Dossot, ${ }^{8}$ Grégoire Herzog, ${ }^{8}$ and Micheál D. Scanlon. ${ }^{1,2,9 *}$

${ }^{1}$ Department of Chemical Sciences, School of Natural Sciences, University of Limerick (UL), Limerick V94 T9PX, Ireland

${ }^{2}$ The Bernal Institute, University of Limerick (UL), Limerick V94 T9PX, Ireland

${ }^{3}$ School of Chemistry, National University of Ireland, Galway, University Road, Galway H91

TK33, Ireland

${ }^{4}$ School of Chemistry, University College Cork, Cork T12 YN60 Ireland

${ }^{5}$ Micro-Nano Systems Centre, Tyndall National Institute, Lee Maltings, Cork T12 R5CP, Ireland

${ }^{6}$ Environment Research Institute, University College Cork, Lee Road, Cork T23 XE10, Ireland

${ }^{7}$ Department of Physics, School of Natural Sciences, University of Limerick (UL), Limerick V94 T9PX, Ireland

${ }^{8}$ CNRS-Université de Lorraine, LCPME UMR 7564, 405 Rue de Vandoeuvre, 54600 Villerslès-Nancy, France

${ }^{9}$ The Advanced Materials and Bioengineering Research (AMBER) centre

*corresponding author: micheal.scanlon@ul.ie

Table of Contents

\begin{tabular}{|c|c|}
\hline Supplementary Figures and Tables & $\mathbf{P 2}$ \\
\hline - $\quad$ Supplementary Fig. 1 & $\mathbf{P 2}$ \\
\hline - $\quad$ Supplementary Fig. 2 & P3 \\
\hline - $\quad$ Supplementary Fig. 3 & $\mathbf{P 4}$ \\
\hline - $\quad$ Supplementary Fig. 4 & P6 \\
\hline - $\quad$ Supplementary Fig. 5 & P7 \\
\hline - $\quad$ Supplementary Fig. 6 & P8 \\
\hline - $\quad$ Supplementary Fig. 7 & P9 \\
\hline - Supplementary Table 1 & P9 \\
\hline - $\quad$ Supplementary Fig. 8 & $\mathbf{P 1 0}$ \\
\hline - $\quad$ Supplementary Fig. 9 & $\mathbf{P 1 0}$ \\
\hline - $\quad$ Supplementary Table 2 & P12 \\
\hline Supplementary Experimental Methods & $\mathbf{P 1 3}$ \\
\hline ○ In situ microscopy & $\mathbf{P 1 3}$ \\
\hline - Supplementary Fig. 10 & $\mathbf{P 1 3}$ \\
\hline ○ Molecular dynamic simulations & P14 \\
\hline$\circ$ Photocurrent transient measurements & $\mathbf{P 2 0}$ \\
\hline - $\quad$ Supplementary Fig. 11 & $\mathbf{P} 20$ \\
\hline - $\quad$ Supplementary Fig. 12 & $\mathbf{P 2 0}$ \\
\hline - Supplementary Fig. 13 & $\mathbf{P 2 1}$ \\
\hline Supplementary References & $\mathbf{P} 22$ \\
\hline
\end{tabular}




\section{Supplementary Figures and Tables}

a

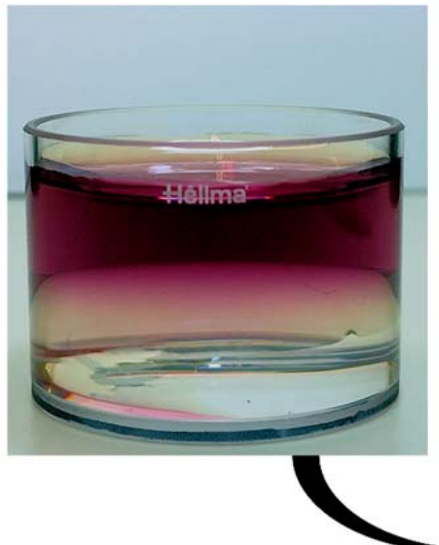

Spontaneous self-assembly

of porphyrin interfacial

nanostructures b

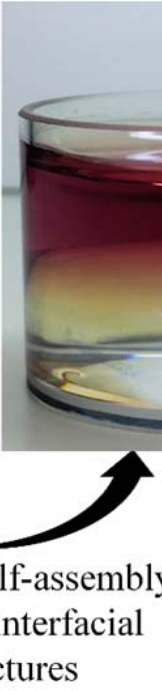

C

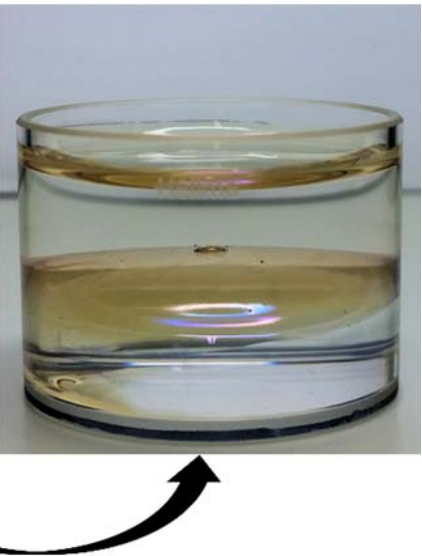

Replacement of the bulk porphyrin solution with

"blank" citrate buffer.

Supplementary Fig. 1 | Methodology of porphyrin interfacial nanostructure formation. a, Aqueous solutions of $\mathrm{ZnTPPc}$ or $\mathrm{H}_{2} \mathrm{TPPc}$ were typically prepared with $50 \mu \mathrm{M}$ porphyrin present. Critically, the $\mathrm{pH}$ of the aqueous solution was adjusted using a $10 \mathrm{mM}$ ionic strength lithium citrate buffer to match the $\mathrm{pKa}$ of the 4-carboxyphenyl substituents $\left(\mathrm{pKa}^{\mathrm{COOH}}=5.8\right)$. Subsequently, aqueous solutions at $\mathrm{pH} 5.8$ were contacted with $\alpha, \alpha, \alpha$-trifluorotoluene (TFT), leading to a well-defined aqueous $\mid$ organic interface. Note the top phase is the aqueous phase. b, Upon contact, the clear formation of porphyrin interfacial nanostructures (Por-INs) was immediately seen visually as a yellow/green complexion (image taken after one hour of contact). c, To isolate the Por-INs at the interface, the upper $50 \%$ of the volume of the aqueous phase was carefully removed by a pipette and replaced with porphyrin-free lithium citrate buffer. This procedure was repeated until no porphyrin was detectable in the aqueous phase by UV/vis spectroscopy. The Por-IN film remained intact and stable, with no redissolution observed after 1 day. 


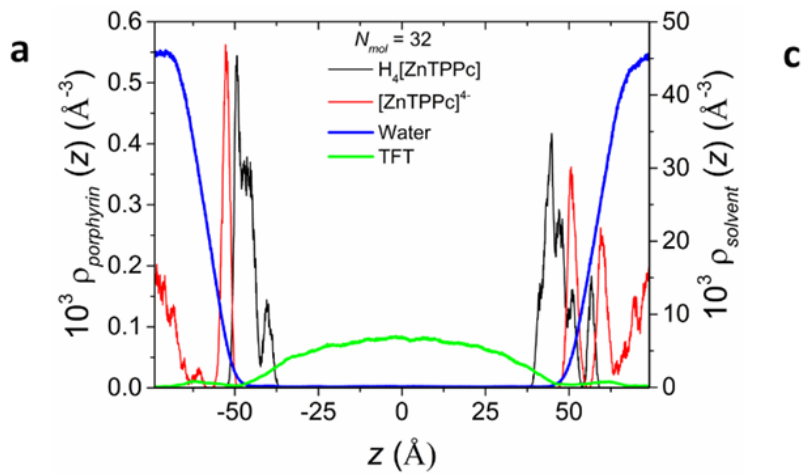

C
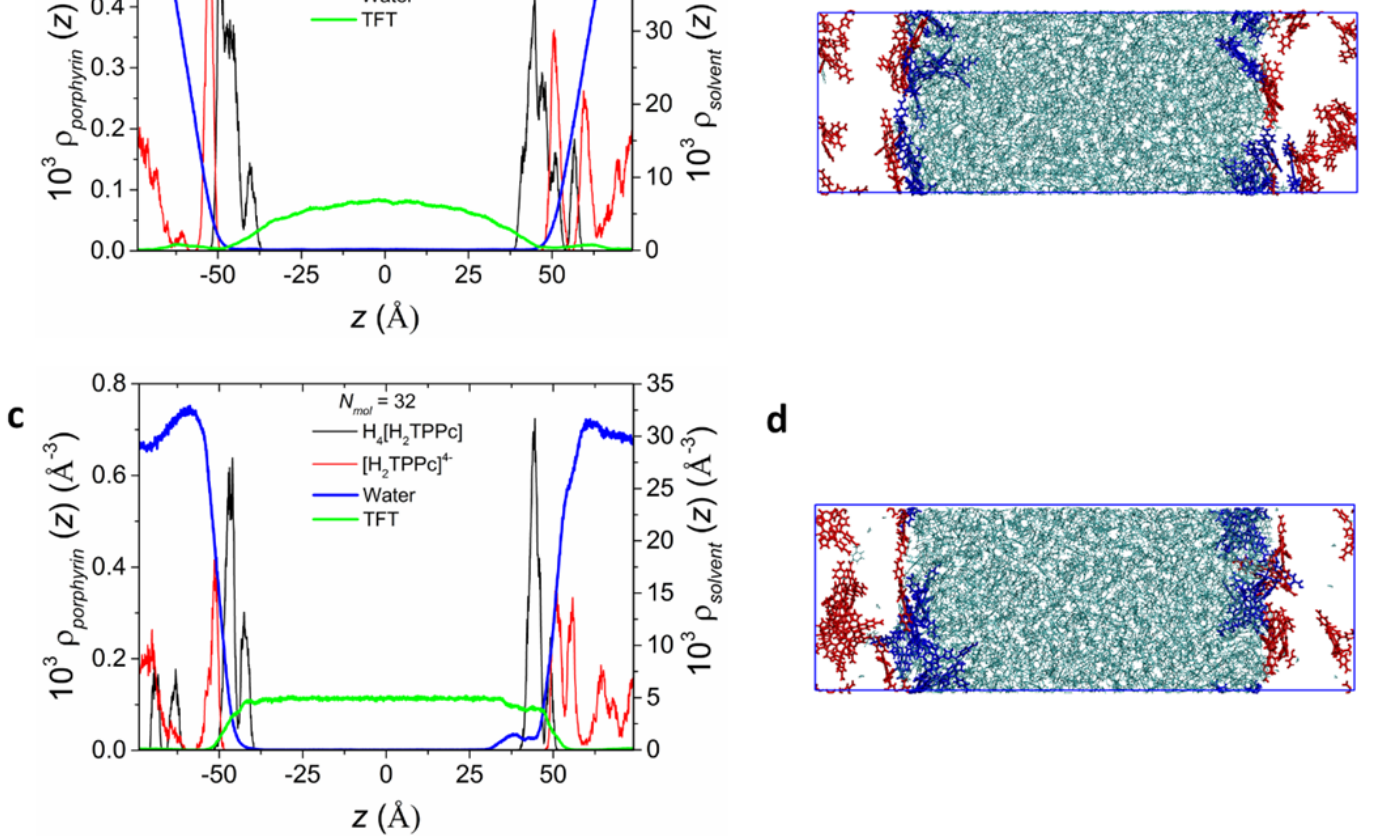

d

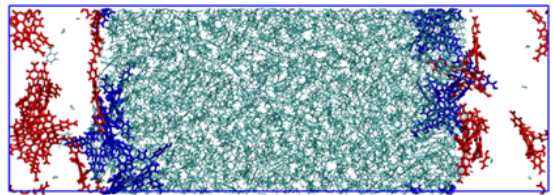

Supplementary Fig. 2 | Molecular dynamic studies demonstrating the layer-by-layer formation of the porphyrin interfacial nanostructures at the water | TFT interface. a, Density $(\rho)$ profiles mimicking the situation at $\mathrm{pH} 5.8\left(=\mathrm{pKa} \mathrm{a}^{\mathrm{COOH}}\right)$, averaged over $10 \mathrm{~ns}$ of molecular dynamics. The simulation consists of 16 fully deprotonated [ZnTPPc] $]^{4-}$ molecules (red lines) and 16 fully protonated $\mathrm{H}_{4}[\mathrm{ZnTPPc}]$ molecules (black lines). The density profiles of water (blue line) and TFT (green line) are also shown. b, A simulation snapshot of the water | TFT | water density profile with $16[\mathrm{ZnTPPc}]^{4-}$ (red) and $16 \mathrm{H}_{4}[\mathrm{ZnTPPc}]$ (blue) molecules present in the aqueous phase. c, The density profile and $\mathbf{d}$, simulation snapshot of the water $\mid$ TFT | water density profiles for $\mathrm{H}_{2}$ TPPc adsorption, averaged over $10 \mathrm{~ns}$ of molecular dynamics.

Discussion | Free energy profiles (PMF) for the porphyrins at the water | TFT interface (Fig. 1d) demonstrate that the charged $[\mathrm{ZnTPPc}]^{4-}$ or $\left[\mathrm{H}_{2} \mathrm{TPPc}\right]^{4-}$ species, being more hydrophilic, have a free energy minimum approximately 4 to $5 \AA$ from the interface itself, while the neutral $\mathrm{H}_{4}\left[\mathrm{H}_{2} \mathrm{TPPc}\right]$ or $\mathrm{H}_{4}[\mathrm{ZnTPPc}]$ molecules lie closer to the interface or on the TFT side of the interface. From the free energy profiles it can be seen that the porphyrins are only weakly bound to the interface, with desorption (into the aqueous layer) free energies of $\sim 24 \mathrm{~kJ} \cdot \mathrm{mol}^{-1}$ and $\sim 48 \mathrm{~kJ} \cdot \mathrm{mol}^{-1}$ for the charged and neutral species, respectively. A significantly higher barrier exists $\left(>200 \mathrm{~kJ} \cdot \mathrm{mol}^{-1}\right)$ for the penetration of these molecules into the TFT layer, indicative of their highly hydrophilic nature. Meanwhile, the neutral porphyrins are both somewhat hydrophobic, with a lower barrier to enter the TFT layer. For $\mathrm{H}_{4}\left[\mathrm{H}_{2} \mathrm{TPP}\right]$ the desorption free energy (into the TFT layer) is similar to that for the charged porphyrins (into the aqueous phase). This difference in the location of charged and neutral molecules affects the assembly of porphyrin molecules at the interface (Supplementary Fig. 2 ). Due to their more hydrophobic nature, the neutral porphyrins reside on the aqueous-TFT interface, forming an interfacial layer. The charged porphyrins partially adsorb onto this, with the neutral molecules acting as a template for the formation of the multilayer porphyrin interfacial nanostructures (Por-INs). 

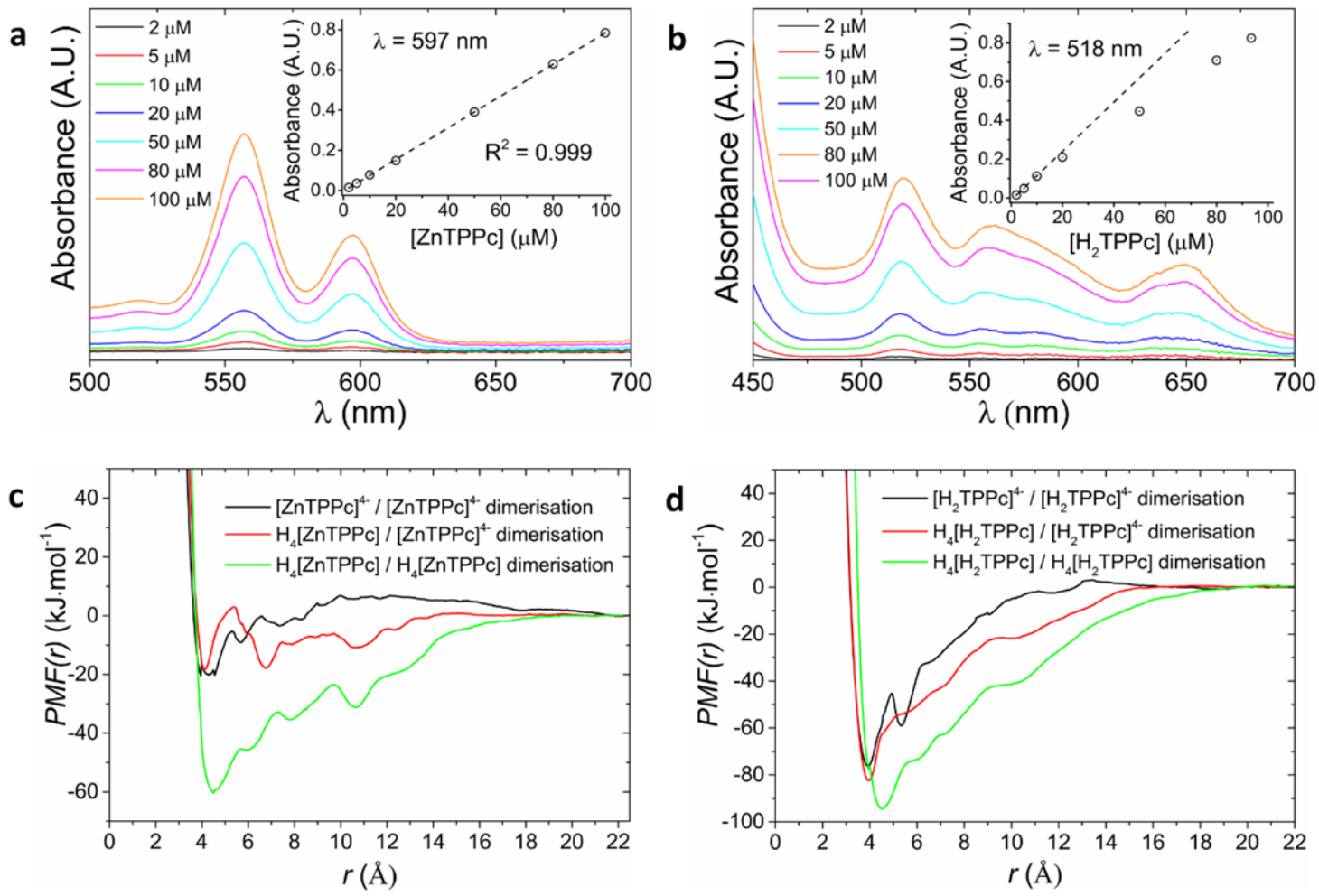

Supplementary Fig. 3 | Investigating the tendency of ZnTPPc and $\mathrm{H}_{2}$ TPPc molecules in the bulk aqueous solution to dimerise or aggregate as a function of porphyrin concentration. UV/vis absorption spectra of aqueous solutions of increasing concentrations of a, ZnTPPc (2 to $100 \mu \mathrm{M})$ and $\mathbf{b}, \mathrm{H}_{2}$ TPPc $(2$ to $100 \mu \mathrm{M})$ in lithium citrate buffer $(10 \mathrm{mM}$ ionic strength, $\mathrm{pH}$ 5.8). Insets: The increase in absorbance as a function of porphyrin concentration. Dimerisation free energies were determined using potential of mean force (PMF) calculations. PMF calculations were performed between both deprotonated and protonated c, ZnTPPc and d, $\mathrm{H}_{2}$ TPPc molecules to mimic (i) highly alkaline pH conditions with predominantly the anionic $[\mathrm{ZnTPPc}]^{4-}$ or $\left[\mathrm{H}_{2} \mathrm{TPPc}\right]^{4-}$ species present, (ii) $\mathrm{pKa} \mathrm{aOOH}^{\mathrm{COH}}$ conditions with 1:1 ratios of $[\mathrm{ZnTPPc}]^{4-}-\mathrm{H}_{4}[\mathrm{ZnTPPc}]$ or $\left[\mathrm{H}_{2} \mathrm{TPPc}\right]^{4-}-\mathrm{H}_{4}\left[\mathrm{H}_{2} \mathrm{TPPc}\right]$ species in solution, and (iii) $\mathrm{pH}$ conditions with predominately $\mathrm{H}_{4}$ [ZnTPPc] or $\mathrm{H}_{4}\left[\mathrm{H}_{2} \mathrm{TPPc}\right]$ molecules present in the range of $1>\mathrm{pH}<5$.

Discussion | For ZnTPPc, no deviation from the Beer-Lambert Law was observed as determined from the linear dependence of the absorbance of the Q band at $597 \mathrm{~nm}$ with increasing ZnTPPc concentration in solution (Supplementary Fig. 3a). Although a linear range of $2-100 \mu \mathrm{M}$ is shown in Figure Supplementary Fig. 3a, this was seen to extend as far as $500 \mu \mathrm{M}$ (data not shown). Previous studies by Pasternack et al. have also concluded that $\mathrm{ZnTPPc}$ remains in a non-aggregated monomeric form at $\mathrm{pH} 6.8$, i.e., at $\mathrm{pH}$ values more alkaline than $\mathrm{pKa} \mathrm{aOH}^{\mathrm{COH}}$, even in an aqueous solution with 10-times the ionic strength investigated herein. ${ }^{1}$ This ability to resist dimerisation, or more extensive aggregation, in aqueous solutions is attributed to the penta-coordination of the zinc atom in ZnTPPc, with a water molecule occupying the axial position. ${ }^{2-5}$ The axial water ligand prevents close approach of porphyrin molecules. More subtly, axial coordination of metalloporphyrins leads to the metal ion being displaced from the porphyrin ring plane. ${ }^{6}$ The latter may have a disruptive effect on the $\pi$-electron density distribution within the core of the macrocycle, weakening the Van der Waals interactions responsible for dimer or higher aggregate formation with other porphyrin monomers. 
In comparison, free-base porphyrins, such as $\mathrm{H}_{2} \mathrm{TPPc},{ }^{7,8}$ and metalloporphyrins with a coordination number of four, such as CuTPPc, that lack hydration in the axial position ${ }^{1,3,9}$ dimerises and aggregate rapidly in aqueous solutions at $\mathrm{pH}$ values more alkaline than $\mathrm{pKa} \mathrm{a}^{\mathrm{COOH}}$ in the presence of added electrolyte. Even modest amounts of added electrolyte will reduce the coulombic barrier to the close approach of other ionic species, such as another anionic $\mathrm{H}_{2}$ TPPc molecule, thereby leading to dimerisation and aggregation at a certain concentration of $\mathrm{H}_{2}$ TPPc in solution. The latter has been reported as $>10 \mu \mathrm{M}$ in $10 \mathrm{mM}$ ionic strength buffer or $>1 \mu \mathrm{M}$ with $100 \mathrm{mM}$ of added electrolyte. ${ }^{8}$ In broad agreement with these previous findings, we see a deviation from linearity of the absorbance of the Q band at 518 $\mathrm{nm}$ with increasing $\mathrm{H}_{2}$ TPPc concentration in solution (Supplementary Fig. 3b). The latter is indicative of $\mathrm{H}_{2}$ TPPc dimer formation for concentrations $>10 \mu \mathrm{M}$ in $10 \mathrm{mM}$ ionic strength lithium citrate buffer at $\mathrm{pH}$ 5.8. However, under these conditions no higher aggregates of $\mathrm{H}_{2}$ TPPc are formed, i.e. no spectral broadening or blue or red-shifting of the Soret or Q bands was observed, and no $\mathrm{H}_{2}$ TPPc aggregates were visible to the eye in solution.

For ZnTPPc the dimerisation free energy (taken to be the depth of the minimum at $r \sim$ $4 \AA$ ) varies significantly with the protonation state of the molecule, with the dimerisation free energy for the $\mathrm{H}_{4}[\mathrm{ZnTPPc}]-\mathrm{H}_{4}[\mathrm{ZnTPPc}]$ pair being approximately three times that of the other combinations (Supplementary Fig. 3c). The increased stability of the $\mathrm{H}_{4}[\mathrm{ZnTPPc}$ $\mathrm{H}_{4}[\mathrm{ZnTPPc}]$ pair compared to the others may be due to stronger hydrophobic interactions. The latter is in agreement with the kinetic instability of the neutral porphyrin species, experimentally observed to precipitate rapidly for $\mathrm{pH}$ conditions across the range of $4.0 \leq \mathrm{pH}$ $\leq 5.5$ (see Supplementary Fig. 4). Across this $\mathrm{pH}$ range, the steric influence of the axial water molecule alone is no longer sufficient to prevent the close approach of two $\mathrm{H}_{4}[\mathrm{ZnTPPc}]$ species due to minimisation of electrostatic repulsion, leading to stronger hydrophobic interactions. The PMF calculations show significant structure with a number of minima spaced $\sim 2-3 \AA$ apart. These may arise due to water molecules interacting with the zinc centre. Such structure is much less apparent for $\mathrm{H}_{2}$ TPPc (Supplementary Fig. 3d), which lacks the zinc centre. For this case the dimerisation free energy is higher than for ZnTPPc and is less influenced by the protonation states of the molecules. Again, this finding fits with the experimentally observed deviation of $\mathrm{H}_{2}$ TPPc from the Beer-Lambert law due to rapid dimerisation in aqueous solutions (Supplementary Fig. 3b), even at $\mathrm{pH}$ values $\geq \mathrm{pKa} \mathrm{aOOH}^{\mathrm{COH}}$ where $\mathrm{ZnTPPc}$ remains in monomeric form. 

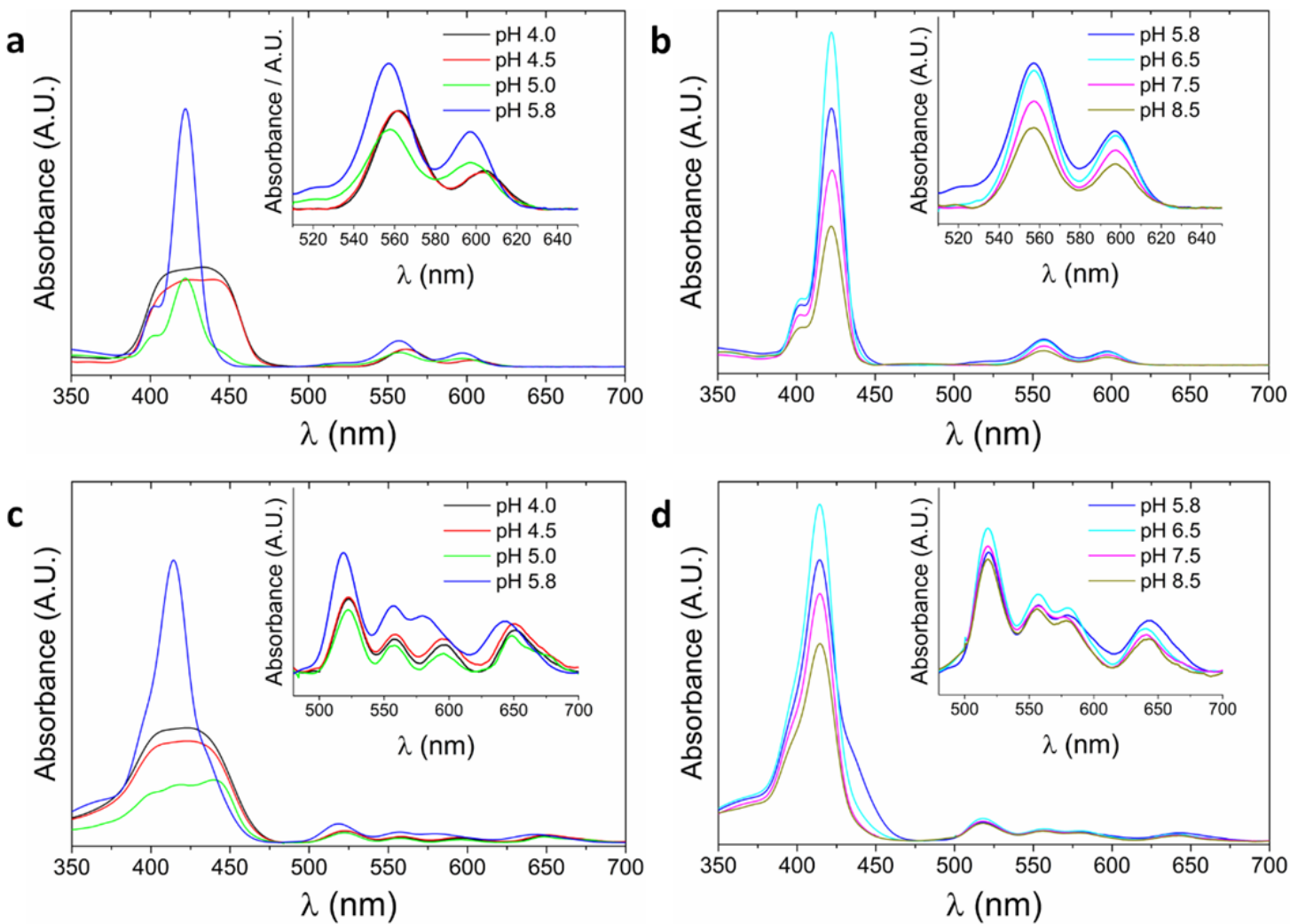

Supplementary Fig. 4 Investigating the tendency of the porphyrin molecules in the aqueous solution to aggregate: influence of $\mathbf{p H}$. UV/vis absorbance spectra of aqueous solutions of $50 \mu \mathrm{M} Z \mathrm{ZnTPPc}$ at $\mathrm{pH}$ conditions a, more acidic and $\mathbf{b}$, more alkaline than $\mathrm{pKa} \mathrm{a}^{\mathrm{COOH}}\left(=\mathrm{pH}\right.$ 5.8). Identical experiments were performed with $50 \mu \mathrm{M} \mathrm{H}_{2} \mathrm{TPPc}$ at $\mathrm{pH}$ conditions c, more acidic and $\mathbf{d}$, more alkaline than $\mathrm{pKa}{ }^{\mathrm{COOH}}$. The $\mathrm{pH}$ of each aqueous solution was adjusted using citric acid and $\mathrm{LiOH}$. The ionic strength at each $\mathrm{pH}$ condition was maintained at $10( \pm 2) \mathrm{mM}$. Insets: The Q-band region of the ZnTPPc and $\mathrm{H}_{2} \mathrm{TPPc}$ $\mathrm{UV} / \mathrm{vis}$ absorbance spectra.

Discussion | As the $\mathrm{pH}$ becomes progressively more acidic than $\mathrm{pKa} \mathrm{a}^{\mathrm{COOH}}$, the equilibrium is displaced towards the neutral $\mathrm{H}_{4}$ [ZnTPPc] or $\mathrm{H}_{4}\left[\mathrm{H}_{2} \mathrm{TPPc}\right]$ species relative to the anionic $[\mathrm{ZnTPPc}]^{4-}$ or $\left[\mathrm{H}_{2} \mathrm{TPPc}\right]^{4-}$ species. As noted in Supplementary Figs. 3c and 3d, the $\mathrm{H}_{4}[\mathrm{ZnTPPc}]-\mathrm{H}_{4}[\mathrm{ZnTPPc}]$ pair (or $\mathrm{H}_{4}\left[\mathrm{H}_{2} \mathrm{TPPc}\right]-\mathrm{H}_{4}\left[\mathrm{H}_{2} \mathrm{TPPc}\right]$ pair) is stable due to strong hydrophobic interactions, leading to kinetic instability and rapid bulk aggreagtion. The latter explains the reduction in peak intensity and broadening of the Soret bands across the range of $4.0 \leq \mathrm{pH} \leq 5.5$ for $\mathrm{ZnTPPc}$ and $\mathrm{H}_{2}$ TPPc in Supplementary Figs. 4a and 4c, respectively. 

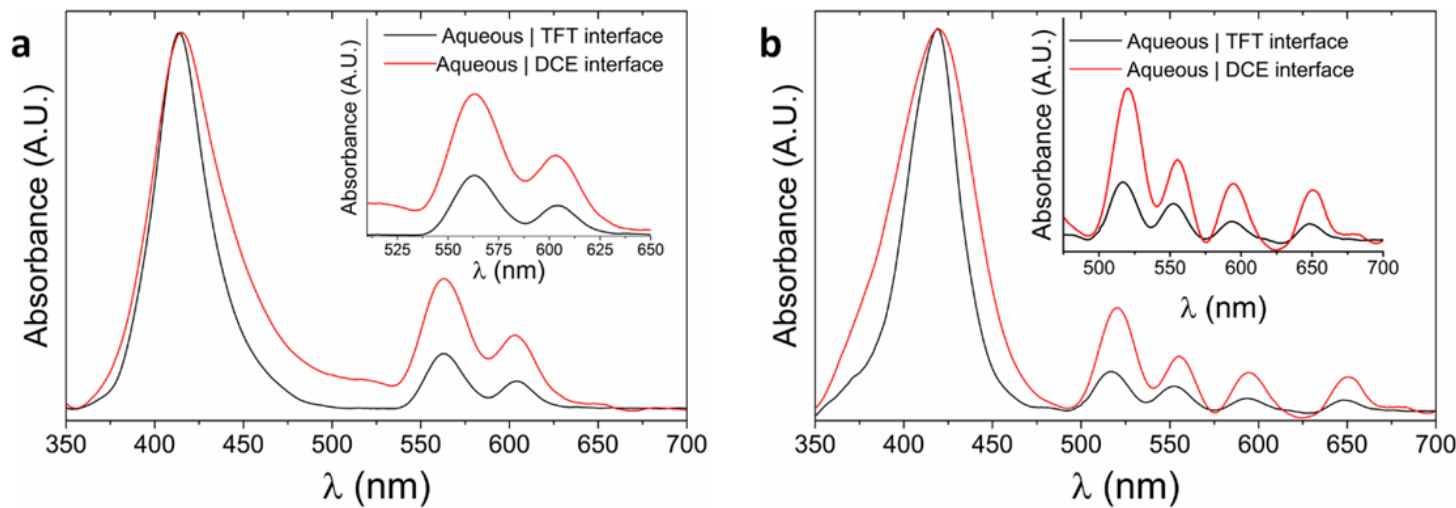

Supplementary Fig. 5 | Investigating the formation of porphyrin interfacial aggregates at the aqueous-organic interface: influence of the organic solvent. UV/vis absorbance spectra of a, ZnPor-INs and $\mathbf{b}, \mathrm{H}_{2}$ Por-INs self-assembled as described in Fig. 1 for 24 hours with $50 \mu \mathrm{M}$ porphyrin in the aqueous phase and either an $\alpha, \alpha, \alpha$-trifluorotoluene (TFT) or 1,2-dichloroethane (DCE) organic phase. The UV/vis spectra with each organic solvent were normalized to the maximum absorbance of the Soret bands of the ZnPor-INs $\left(\lambda_{\max }=414 \mathrm{~nm}\right)$ or $\mathrm{H}_{2}$ Por-INs $\left(\lambda_{\max }=420 \mathrm{~nm}\right)$, respectively. Insets: The Q-band region of the ZnPor- and $\mathrm{H}_{2}$ Por-INs UV/vis absorbance spectra. 

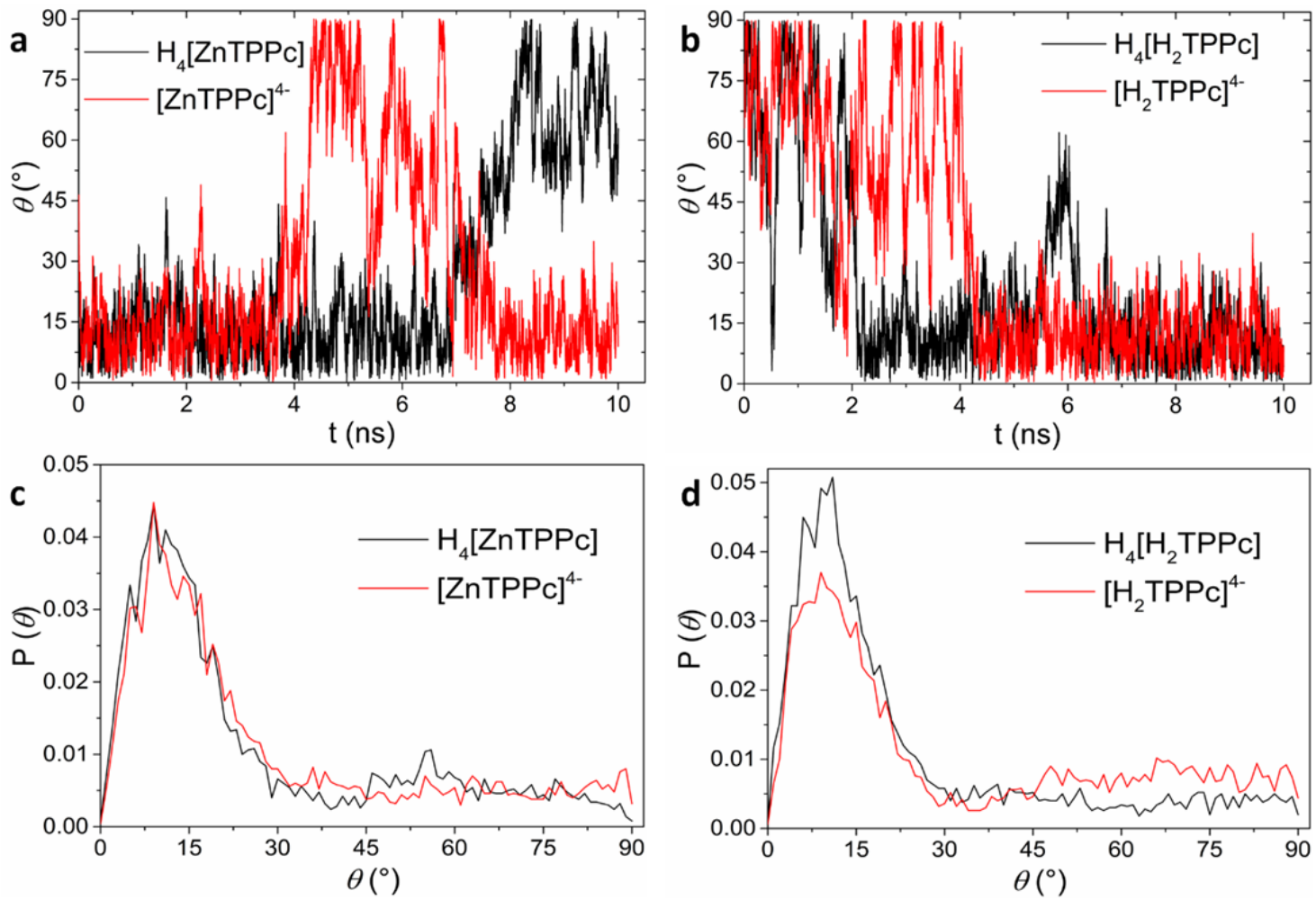

Supplementary Fig. 6 | Simulations of the average angle of orientation, $\theta$, of fully protonated (black lines) and fully deprotonated (red lines) a, ZnTPPc and $\mathbf{b}, \mathrm{H}_{2}$ TPPc molecules versus time at the water | TFT interface. Probability distributions of the angle of orientation, $\mathrm{P}(\theta)$, of fully protonated (black lines) and fully deprotonated (red lines) c, ZnTPPc and d, $\mathrm{H}_{2}$ TPPc molecules average over $10 \mathrm{~ns}$ of molecular dynamics (MD).

Discussion | Regardless of the presence of the zinc centre and protonation state, the molecules lie in the plane of the interface, with a dihedral angle between the porphyrin plane and the interface close to $0^{\circ}$. However, there is a significant degree of orientational freedom (Supplementary Fig. 6a,b), with all molecules adopting a range of orientations relative to the interface. This is reflected in the orientational angle probability distributions (Supplementary Fig. 6c,d) which have peaks at low $\left(<15^{\circ}\right)$ angle but remain non-zero for all angles. These findings are in line with previous MD studies for the adsorption of symmetrically substituted hydrophilic porphyrin molecules to aqueous | hydrophobic phospholipid membrane interfaces that revealed the central porphyrin rings stay almost flat at the bilayer surface once equilibrium was reached. ${ }^{10}$ Thus, MD analysis strongly infers that the molecules primarily lie flat in the plane of the liquid $\mid$ liquid interface. 

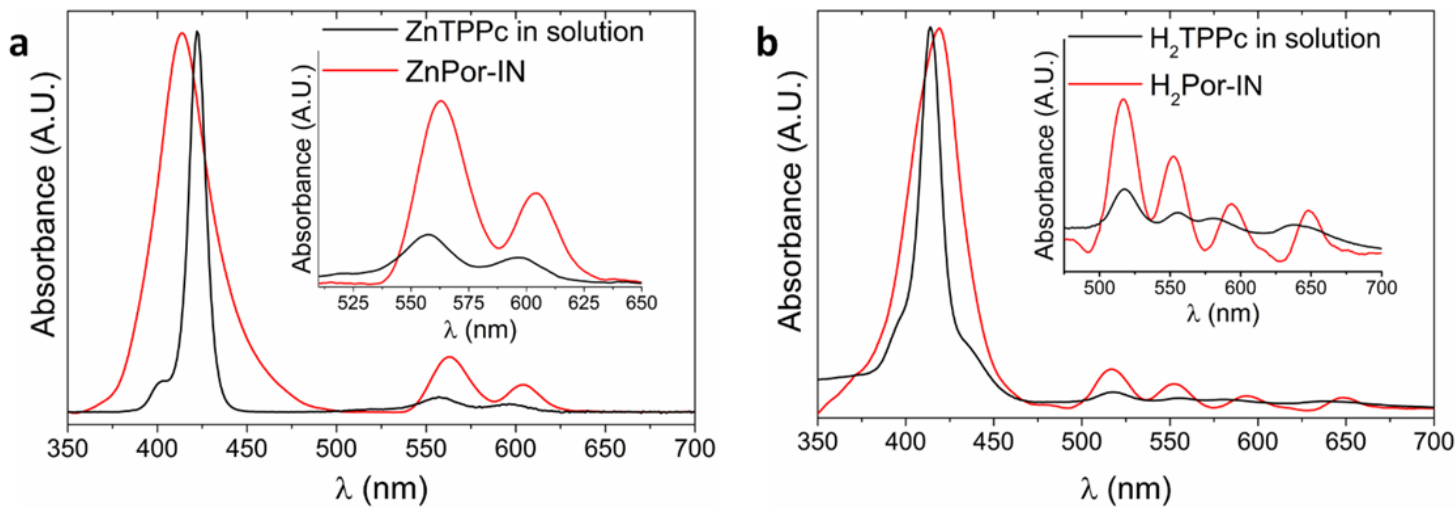

Supplementary Fig. 7 | Comparison of the in situ UV/vis absorption spectra for a, ZnTPPc in solution versus ZnPor-INs and $\mathbf{b}, \mathrm{H}_{2}$ TPPc in solution versus $\mathrm{H}_{2}$ Por-INs. The porphyrin aqueous solutions consisted of either $50 \mu \mathrm{M}$ ZnTPPc or $\mathrm{H}_{2}$ TPPc in lithium citrate buffer (10 $\mathrm{mM}$ ionic strength, $\mathrm{pH}$ 5.8). The Por-INs were self-assembled as described in Fig. 1 for 24 hours with either $50 \mu \mathrm{M} \mathrm{ZnTPPc}$ or $\mathrm{H}_{2}$ TPPc in the aqueous phase. The in situ UV/vis absorbance spectra of the Por-INs were normalized to the maximum absorbance of the Soret bands of ZnTPPc $\left(\lambda_{\max }=422 \mathrm{~nm}\right)$ or $\mathrm{H}_{2} \mathrm{TPPc}\left(\lambda_{\max }=414 \mathrm{~nm}\right)$ in solution, respectively. Insets: The $\mathrm{Q}$ band region of the in situ $\mathrm{UV} / \mathrm{vis}$ absorption spectra.

Supplementary Table 1 | The absorption maxima $\left(\lambda_{\text {max. }}\right)$ of the Soret and Q bands of both ZnTPPc and $\mathrm{H}_{2}$ TPPc in $10 \mathrm{mM}$ lithium citrate buffer solution (pH 5.8), and their corresponding Por-INs self-assembled at the immiscible water $\mid$ TFT interface.

\begin{tabular}{|c|c|c|c|c|c|}
\hline \multirow[b]{2}{*}{ Porphyrin species } & \multicolumn{5}{|c|}{ Absorption peaks (nm) } \\
\hline & Soret & \multicolumn{2}{|c|}{$Q(1,0)$} & \multicolumn{2}{|c|}{$Q(0,0)$} \\
\hline ZnTPPc in solution & $422(11)$ & \multicolumn{2}{|c|}{557} & \multicolumn{2}{|c|}{596} \\
\hline ZnTPPc interfacial nanostructures & $413(35)$ & \multicolumn{2}{|c|}{563} & \multicolumn{2}{|c|}{604} \\
\hline & Soret & $\mathrm{Q}(1,0) y$ & $Q(0,0) y$ & $Q(1,0) x$ & $\mathrm{Q}(\mathbf{0 , 0}) \mathrm{x}$ \\
\hline $\mathrm{H}_{2} \mathrm{TPPc}$ in solution & $414(15)$ & 518 & 555 & 582 & 639 \\
\hline $\mathrm{H}_{2} \mathrm{TPPc}$ interfacial nanostructures & $419(34)$ & 517 & 552 & 593 & 648 \\
\hline
\end{tabular}

${ }^{a}$ Accuracy of the absorption maxima is $\pm 1 \mathrm{~nm} .{ }^{b}$ Values in the brackets are the full width at half maximum (FWHM) of the Soret bands. The latter are provided to highlight the extent of spectral broadening upon porphyrin nanostructure formation.

Discussion | The $\lambda_{\text {max. }}$ values of the Soret and Q bands in solution are within $\pm 2 \mathrm{~nm}$ of previously reported values for spectra of $\mathrm{ZnTPPc}^{11}$ and $\mathrm{H}_{2} \mathrm{TPPc},{ }^{7,12-15}$ respectively, recorded in comparable aqueous phases. 

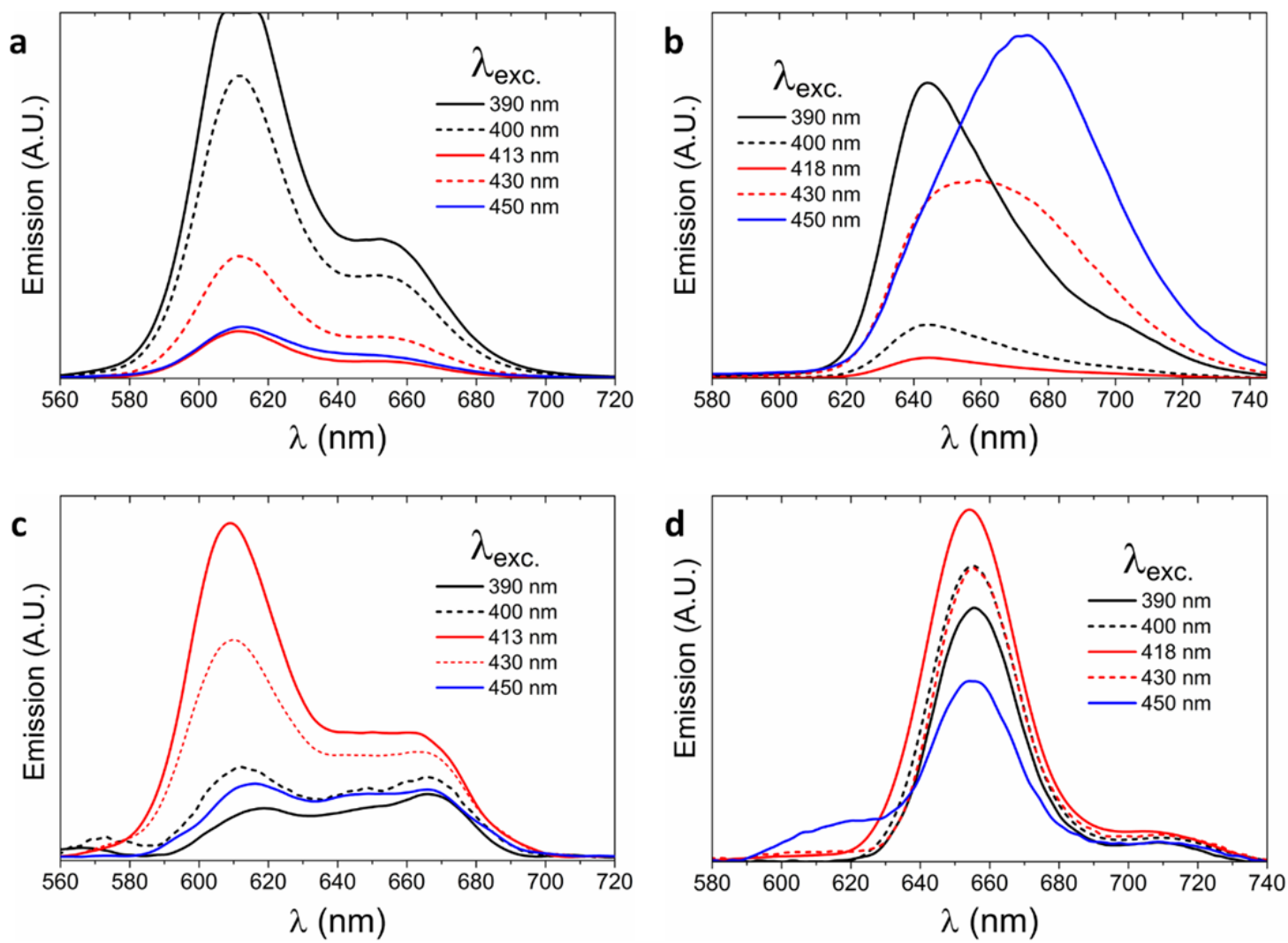

Supplementary Fig. 8 | In situ steady-state fluorescence spectra as a function of excitation wavelength $\left(\lambda_{\text {exc. }}\right)$ for $\mathbf{a}, 50 \mu \mathrm{M} Z \mathrm{ZnTPPc}$ and $\mathbf{b}, 50 \mu \mathrm{M} \mathrm{H}_{2} \mathrm{TPPc}$ in $10 \mathrm{mM}$ lithium citrate buffer ( $\mathrm{pH}$ 5.8), and c, ZnPor-INs and d, $\mathrm{H}_{2}$ Por-INs self-assembled as described in Fig. 1 for 24 hours with $50 \mu \mathrm{M} Z n T P P c$ or H2TPPc, respectively, in the aqueous phase.
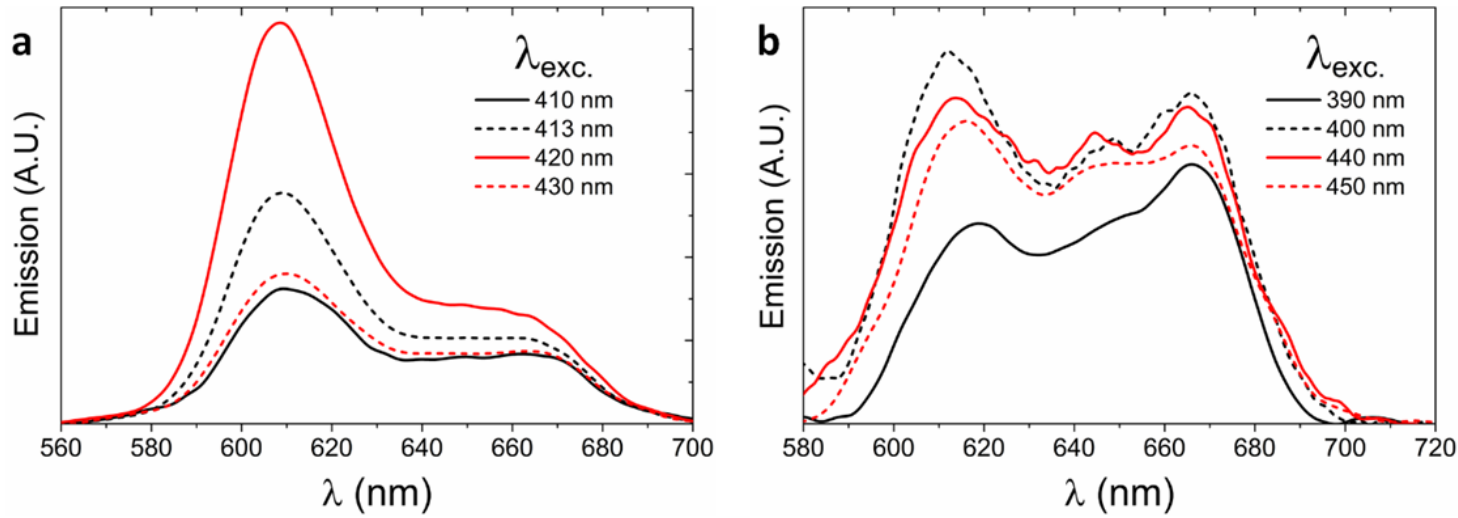

Supplementary Fig. 9 | Two different emission regimes were observed for the in situ steadystate fluorescence spectra of the ZnPor-INs as a function of excitation wavelength $\left(\lambda_{\text {exc. }}\right)$.

Discussion | In situ steady-state fluorescence spectroscopy was employed to investigate the effect of incident radiation falls within the Soret band (Kasha's rule). Thus, if a single species of uniform electronic structure was present, only the intensity of the emissions but not the emission spectra profiles should be affected by varying $\lambda_{\text {exc. }}$ within the Soret band. However, if a number of species with varying electronic structures were present, both the emission intensities and spectral profiles should vary significantly upon changing $\lambda_{\text {exc. }}$ within the Soret band. The latter would therefore be expected from a mixture of domains with slightly 
different geometric arrangements of the porphyrin molecules due to their excitation at slightly different wavelengths. Quantitative comparison of emission intensities of ZnTPPc in buffer solution and the Por-INs was hampered by scattering due to the experimental configuration (Supplementary Fig. 10).

The emission profiles of $50 \mu \mathrm{M}$ ZnTPPc in solution were independent of $\lambda_{\text {exc. }}$ across the Soret band indicating the presence of a monomeric ZnTPPc species only in solution (Supplementary Fig. 8a). A dependence of the emission profile of $50 \mu \mathrm{M} \mathrm{H}_{2} \mathrm{TPPc}$ in solution on $\lambda_{\text {exc. }}$ across the Soret band was observed due to the co-existence of the monomer and dimer species in solution (Supplementary Fig. 8b). The latter was expected based on previous observations from in situ UV/vis spectroscopy (see Supplementary Fig. 3b). The emission profile of the ZnPor-INs was highly dependent on $\lambda_{\text {exc. }}$ across the Soret band. Two emission regimes were tentatively assigned, each potentially corresponding to distinct domains with slightly different geometric arrangements of the porphyrin molecules (Supplementary Figs. $8 \mathrm{c}$ and 9). The emission profile of the $\mathrm{H}_{2}$ Por-INs was independent of $\lambda_{\text {exc. }}$ across the Soret band (Supplementary Fig. 8d), suggesting either a single nanostructure of $\mathrm{H}_{2}$ TPPc was formed at the interface, or that any different domains in the nanostructure had very similar electronic structures. 
Supplementary Table 2. Assignment of the bands observed in the Raman spectra of the ZnPor- and $\mathrm{H}_{2}$ Por-INs excited at $532 \mathrm{~nm}$ (the experimental data is presented in Fig 4e; note that the peak at $522 \mathrm{~cm}^{-1}$ is due to the underlying silicon substrate).

\begin{tabular}{|c|c|c|}
\hline $\mathbf{H}_{2}$ Por-IN & ZnPor-IN & Assignment \\
\hline 322 & - & $?$ \\
\hline- & 374 & $?$ \\
\hline- & 408 & $?$ \\
\hline 705 & - & Phenyl \\
\hline 824 & - & Phenyl \\
\hline 966 & - & Phenyl \\
\hline 1005 & 1009 & Phenyl, $v\left(\mathrm{C}_{\alpha}-\mathrm{C}_{\mathrm{M}}\right)$ \\
\hline- & 1031 & Phenyl \\
\hline 1086 & 1076 & $\mathrm{~A}_{1 \mathrm{~g}}, \delta_{\mathrm{s}}\left(\mathrm{C}_{\beta}-\mathrm{H}\right)$ \\
\hline 1140 & - & $\mathrm{A}_{1 \mathrm{~g}}, v\left(\mathrm{C}_{\alpha}-\mathrm{N}\right)$ \\
\hline- & 1179 & Phenyl \\
\hline 1241 & 1243 & $v\left(\mathrm{C}_{\mathrm{M}}-\Phi\right)$ \\
\hline 1327 & - & $\mathrm{B}_{1 \mathrm{~g}}, v_{\mathrm{as}}\left(\mathrm{C}_{\alpha}-\mathrm{N}\right)$ \\
\hline 1364 & - & $\mathrm{A}_{1 \mathrm{~g}}, v_{\mathrm{s}}\left(\mathrm{C}_{\alpha}-\mathrm{N}\right)+v_{\mathrm{s}}\left(\mathrm{C}_{\alpha}-\mathrm{C}_{\beta}\right)$ \\
\hline- & 1354 & $\mathrm{~A}_{1 \mathrm{~g}}, v_{\mathrm{s}}\left(\mathrm{C}_{\alpha}-\mathrm{C}_{\beta}\right)+v_{\mathrm{s}}\left(\mathrm{C}_{\alpha}-\mathrm{N}\right)$ \\
\hline 1453 & 1450 & $\mathrm{~B}_{1 \mathrm{~g}}, v_{\mathrm{as}}\left(\mathrm{C}_{\beta}-\mathrm{C}_{\mathrm{M}}\right)$ \\
\hline- & 1496 & $\mathrm{~B}_{1 \mathrm{~g}}, v\left(\mathrm{C}_{\beta}-\mathrm{C}_{\beta}\right)$ \\
\hline 1555 & 1550 & $\mathrm{~A}_{1 \mathrm{~g}}, v\left(\mathrm{C}_{\beta}-\mathrm{C}_{\beta}\right)$ \\
\hline 1606 & 1605 & Phenyl \\
\hline
\end{tabular}

${ }^{a} v$ represents bond stretching and $\delta$ represents bond bending. Subscripts s and as refer to the symmetric and asymmetric vibrations with respect to the pyrrole 2-fold axis for $v\left(\mathrm{C}_{\beta}-\mathrm{H}\right)$, $\delta\left(\mathrm{C}_{\beta}-\mathrm{H}\right), v\left(\mathrm{C}_{\alpha}-\mathrm{N}\right)$, or the methine 2-fold axes for $v\left(\mathrm{C}_{\alpha}-\mathrm{C}_{\beta}\right)$. $\Phi$ represents the phenyl group. ${ }^{b}$ Assignments from references ${ }^{16-19}$.

Discussion | Firstly, the peak at $322 \mathrm{~cm}^{-1}$ for the $\mathrm{H}_{2}$ Por-INs is absent for the ZnPorINs, with two peaks at 374 and $408 \mathrm{~cm}^{-1}$ observed instead. Secondly, the single peak at 1354 $\mathrm{cm}^{-1}$ for the ZnPor-INs is replaced by a doublet at 1327 and $1364 \mathrm{~cm}^{-1}$ for the $\mathrm{H}_{2}$ Por-INs. Furthermore, as noted by Vlčková et al. when comparing surface-enhanced resonance Raman spectra (SERRS) of free-base and silver $\mathrm{H}_{2}$ TPPc species, ${ }^{18}$ a major distinguishing factor is a loss in intensity of the phenyl out-of-plane modes and a gain in intensity of the phenyl inplane modes upon metalation. For example, bands at 705, 824 and $966 \mathrm{~cm}^{-1}$, associated with $\pi_{3}, \pi_{2}$ and $\pi_{1}$ phenyl ring out-of-plane modes (mode orders from Spiro and co-workers) ${ }^{20,21}$ are present in the $\mathrm{H}_{2}$ Por-IN spectra, but absent in the ZnPor-IN spectra. Additionally, the phenyl ring in-plane mode at $1179 \mathrm{~cm}^{-1}$ present in the ZnPor-IN spectra is entirely absent in the $\mathrm{H}_{2}$ Por-IN spectra. 


\section{Supplementary Experimental Methods}

In situ microscopy. The films of Por-INs were very well adhered to the aqueous-TFT interface (see Fig. 1b). This attribute significantly facilitated their subsequent unambiguous in situ spectroscopic characterisation as it allowed the selective removal of the bulk porphyrin molecules from solution. The absorption or emission of light by the latter would otherwise greatly interfere with the selective in situ acquisition of $\mathrm{UV} / \mathrm{vis}$ absorption or fluorescence emission spectra from the Por-INs.

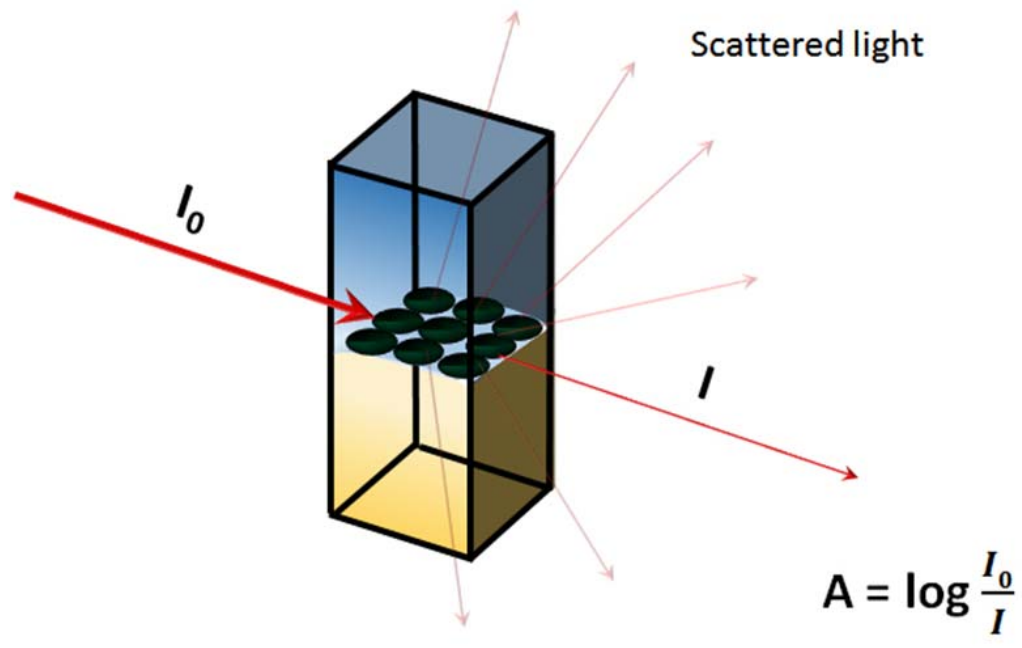

Scattered light

Supplementary Fig. 10 | Schematic of the experimental configuration implemented to obtain in situ UV/vis absorbance and steady-state fluorescence spectra of the Por-INs. 
Molecular dynamic simulations. Simulations of interfacial adsorption and assembly were performed using a pre-equilibrated water $\mid$ TFT interface, consisting water and TFT regions with 4000 water molecules and 1226 TFT molecules, respectively. For the dimerisation free energy calculations two porphyrin molecules were placed in a box containing 4000 water molecules. The porphyrin and TFT molecules were modelled using the Generalised Amber Force Field ${ }^{22}$ and the TIP3P model was used for the water molecules. Charges on the zinc porphyrin unit were found using the Metal Center Parameter Builder. ${ }^{23}$ Charges on the sidechains and TFT were determined from AM1-BCC calculations ${ }^{24,25}$ Bonded potentials for the $\mathrm{Zn}$ atom were taken from the work of Lin and Wang. ${ }^{26}$ Force field setup and parameterisation were performed using the Antechamber program in AmberTools (version 14). Full details of the force field, along with sample input files are detailed vide infra.

All simulations were performed using the LAMMPS molecular dynamics package. ${ }^{27}$ The simulation temperature and pressure were $298 \mathrm{~K}$ and $1 \mathrm{~atm}$, with temperature and pressure controlled using Nose-Hoover thermostat (relaxation time $0.2 \mathrm{ps}$ ) and barostats (relaxation $2 \mathrm{ps}$ ). ${ }^{27}$ For interfacial simulations the box was allowed to vary in the $x$ and $y$ dimensions (the $\mathrm{z}$ box length was held fixed). Electrostatic interactions were evaluated using a particle-particle-particle-mesh sum. ${ }^{28}$ For interface simulations convergence parameter $\alpha=$ $0.263 \mathrm{~A}^{-1}$ and a reciprocal space grid of $36 \times 36 \times 80$ was used, for simulations in bulk water $\alpha=0.278 \mathrm{~A}^{-1}$ and a reciprocal space grid of $40 \mathrm{x} 40 \mathrm{x} 40$ was used. Van der Waals interactions were cut-off at $11 \mathrm{~A}$, with tail corrections applied to both energy and force. Adsorption and dimerization free energies were found using the Adaptive Biasing Force (ABF) method. ${ }^{29,30}$ To assist convergence the full $\mathrm{z}$ and $\mathrm{r}$ range were divided into $5 \mathrm{~A}$ wide windows, with $\mathrm{ABF}$ used to generate the free energy profile in each window.

\section{Force field details}

Atom types. The atom names for the porphyrin are shown below (two rings are given explicitly, atom names for the other rings can be found by equivalence). For the free base the nitrogen atoms NA and $\mathrm{NC}$ are bonded to hydrogens (HA and $\mathrm{HC}$ )

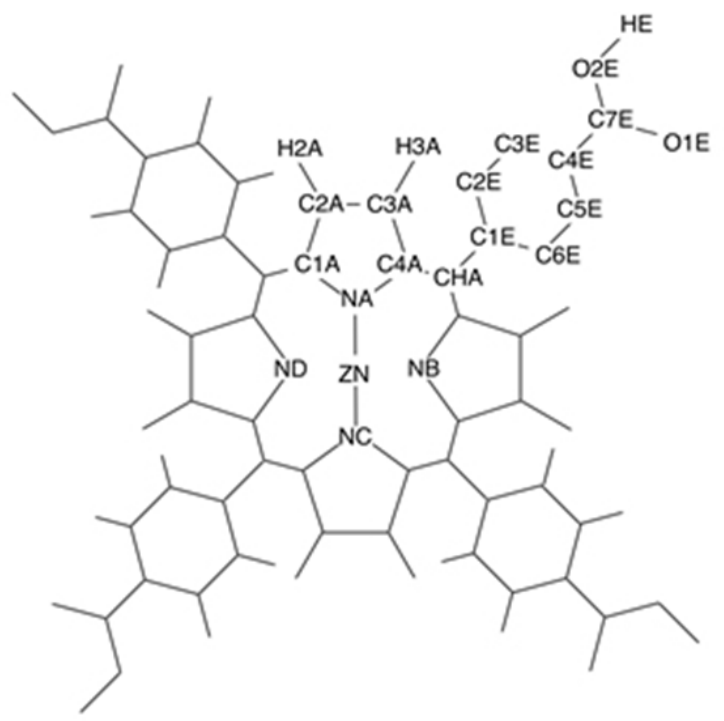


Non-bonded parameters

[ZnTPPc] $^{4-}$

\begin{tabular}{|c|c|c|c|c|}
\hline Atom & Atom type & q/e & $\varepsilon / \mathrm{kcal} \mathrm{mol}^{-1}$ & $\sigma / A$ \\
\hline $\begin{array}{l}\text { C1A, C1B, C1C, } \\
\text { C1D, } \\
\text { C4A, C4B, } \\
\text { C4C,C4D }\end{array}$ & $\mathrm{ca}$ & +0.498 & 0.086 & 3.40 \\
\hline $\begin{array}{l}\mathrm{C} 2 \mathrm{~A}, \mathrm{C} 2 \mathrm{~B}, \mathrm{C} 2 \mathrm{C}, \\
\mathrm{C} 2 \mathrm{D}, \\
\mathrm{C} 3 \mathrm{~A}, \mathrm{C} 3 \mathrm{~B}, \mathrm{C} 3 \mathrm{C}, \\
\mathrm{C} 3 \mathrm{D}\end{array}$ & ca & -0.275 & 0.086 & 3.40 \\
\hline $\begin{array}{l}\text { H2A, H2B, H2C, } \\
\text { H2D, } \\
\text { H3A, H3B, H3C, } \\
\text { H3D }\end{array}$ & ha & +0.165 & 0.015 & 2.60 \\
\hline $\mathrm{NA}, \mathrm{NC}$ & nc & -0.710 & 0.170 & 3.25 \\
\hline $\mathrm{NB}, \mathrm{ND}$ & nd & -0.710 & 0.170 & 3.25 \\
\hline $\begin{array}{l}\text { CHA, CHB, } \\
\text { CHC, CHD }\end{array}$ & $\mathrm{cg}$ & -0.249 & 0.086 & 3.40 \\
\hline $\mathrm{ZN}$ & $\mathrm{ZN}$ & +1.132 & 0.0125 & 1.96 \\
\hline $\begin{array}{l}\text { C1E, C1F, C1G, } \\
\text { C1H }\end{array}$ & ca & -0.162 & 0.086 & 3.40 \\
\hline $\begin{array}{l}\text { C2E, C2F, C2G, } \\
\text { C2H, C6E, C6F, } \\
\text { C6G, C6H }\end{array}$ & $\mathrm{ca}$ & -0.166 & 0.086 & 3.40 \\
\hline $\begin{array}{l}\mathrm{H} 2 \mathrm{E}, \mathrm{H} 2 \mathrm{~F}, \mathrm{H} 2 \mathrm{G}, \\
\mathrm{H} 2 \mathrm{H}, \mathrm{H} 6 \mathrm{E}, \mathrm{H} 6 \mathrm{~F}, \\
\mathrm{H} 6 \mathrm{G}, \mathrm{H} 6 \mathrm{H}\end{array}$ & ha & +0.101 & 0.015 & 2.60 \\
\hline $\begin{array}{l}\mathrm{C} 3 \mathrm{E}, \mathrm{C} 3 \mathrm{~F}, \mathrm{C} 3 \mathrm{G}, \\
\mathrm{C} 3 \mathrm{H}, \mathrm{C} 5 \mathrm{E}, \mathrm{C} 5 \mathrm{~F}, \\
\mathrm{C} 5 \mathrm{G}, \mathrm{C} 5 \mathrm{H}\end{array}$ & ca & -0.109 & 0.086 & 3.40 \\
\hline $\begin{array}{l}\text { H3E, H3F, H3G, } \\
\text { H3H, H5E, H5F, } \\
\text { H5G, H5H }\end{array}$ & ha & +0.148 & 0.015 & 2.60 \\
\hline $\begin{array}{l}\text { C4E, C4F, C4G, } \\
\text { C4H }\end{array}$ & $\mathrm{ca}$ & -0.124 & 0.086 & 3.40 \\
\hline $\begin{array}{l}\mathrm{C} 7 \mathrm{E}, \mathrm{C} 7 \mathrm{~F}, \mathrm{C} 7 \mathrm{G}, \\
\mathrm{C} 7 \mathrm{H}\end{array}$ & $\mathrm{c}$ & +0.906 & 0.086 & 3.40 \\
\hline $\begin{array}{l}\mathrm{O} 1 \mathrm{E}, \mathrm{O} 1 \mathrm{~F}, \mathrm{O} 1 \mathrm{G}, \\
\mathrm{O} 1 \mathrm{H}, \\
\mathrm{O} 2 \mathrm{E}, \mathrm{O} 2 \mathrm{~F}, \mathrm{O} 2 \mathrm{G}, \\
\mathrm{O} 2 \mathrm{H}\end{array}$ & o & -0.834 & 0.210 & 2.96 \\
\hline
\end{tabular}


$\mathrm{H}_{4}[\mathrm{ZnTPPc}]$

\begin{tabular}{|c|c|c|c|c|}
\hline Atom & Atom type & $q / e$ & $\varepsilon / \mathrm{kcal} \mathrm{mol}^{-1}$ & $\sigma / A$ \\
\hline $\begin{array}{l}\mathrm{C} 1 \mathrm{~A}, \mathrm{C} 1 \mathrm{~B}, \mathrm{C} 1 \mathrm{C}, \\
\mathrm{C} 1 \mathrm{D}, \\
\mathrm{C} 4 \mathrm{~A}, \mathrm{C} 4 \mathrm{~B}, \\
\mathrm{C} 4 \mathrm{C}, \mathrm{C} 4 \mathrm{D}\end{array}$ & ca & +0.498 & 0.086 & 3.40 \\
\hline $\begin{array}{l}\mathrm{C} 2 \mathrm{~A}, \mathrm{C} 2 \mathrm{~B}, \mathrm{C} 2 \mathrm{C}, \\
\mathrm{C} 2 \mathrm{D}, \\
\mathrm{C} 3 \mathrm{~A}, \mathrm{C} 3 \mathrm{~B}, \mathrm{C} 3 \mathrm{C}, \\
\mathrm{C} 3 \mathrm{D}\end{array}$ & ca & -0.275 & 0.086 & 3.40 \\
\hline $\begin{array}{l}\text { H2A, H2B, H2C, } \\
\text { H2D, } \\
\text { H3A, H3B, H3C, } \\
\text { H3D }\end{array}$ & ha & +0.165 & 0.015 & 2.60 \\
\hline $\mathrm{NA}, \mathrm{NC}$ & nc & -0.710 & 0.170 & 3.25 \\
\hline $\mathrm{NB}, \mathrm{ND}$ & nd & -0.710 & 0.170 & 3.25 \\
\hline $\begin{array}{l}\text { CHA, CHB, } \\
\text { CHC, CHD }\end{array}$ & $\mathrm{cg}$ & -0.518 & 0.086 & 3.40 \\
\hline $\mathrm{ZN}$ & $\mathrm{ZN}$ & +1.132 & 0.0125 & 1.96 \\
\hline $\begin{array}{l}\text { C1E, C1F, C1G, } \\
\mathrm{C} 1 \mathrm{H}\end{array}$ & $\mathrm{ca}$ & -0.094 & 0.086 & 3.40 \\
\hline $\begin{array}{l}\text { C2E, C2F, C2G, } \\
\text { C2H, C6E, C6F, } \\
\text { C6G, C6H }\end{array}$ & $\mathrm{ca}$ & -0.148 & 0.086 & 3.40 \\
\hline $\begin{array}{l}\mathrm{H} 2 \mathrm{E}, \mathrm{H} 2 \mathrm{~F}, \mathrm{H} 2 \mathrm{G}, \\
\mathrm{H} 2 \mathrm{H}, \mathrm{H} 6 \mathrm{E}, \mathrm{H} 6 \mathrm{~F}, \\
\mathrm{H} 6 \mathrm{G}, \mathrm{H} 6 \mathrm{H}\end{array}$ & ha & +0.141 & 0.015 & 2.60 \\
\hline $\begin{array}{l}\mathrm{C} 3 \mathrm{E}, \mathrm{C} 3 \mathrm{~F}, \mathrm{C} 3 \mathrm{G}, \\
\mathrm{C} 3 \mathrm{H}, \mathrm{C} 5 \mathrm{E}, \mathrm{C} 5 \mathrm{~F}, \\
\mathrm{C} 5 \mathrm{G}, \mathrm{C} 5 \mathrm{H}\end{array}$ & $\mathrm{ca}$ & -0.069 & 0.086 & 3.40 \\
\hline $\begin{array}{l}\text { H3E, H3F, H3G, } \\
\text { H3H, H5E, H5F, } \\
\text { H5G, H5H }\end{array}$ & ha & +0.157 & 0.015 & 2.60 \\
\hline $\begin{array}{l}\text { C4E, C4F, C4G, } \\
\text { C4H }\end{array}$ & $\mathrm{ca}$ & -0.138 & 0.086 & 3.40 \\
\hline $\begin{array}{l}\text { C7E, C7F, C7G, } \\
\text { C7H }\end{array}$ & $\mathrm{c}$ & +0.652 & 0.086 & 3.40 \\
\hline $\begin{array}{l}\text { O1E, O1F, O1G, } \\
\text { O1H }\end{array}$ & o & -0.554 & 0.210 & 2.96 \\
\hline $\begin{array}{l}\mathrm{O} 2 \mathrm{E}, \mathrm{O} 2 \mathrm{~F}, \mathrm{O} 2 \mathrm{G}, \\
\mathrm{O} 2 \mathrm{H}\end{array}$ & oh & -0.608 & 0.210 & 2.96 \\
\hline $\mathrm{HE}, \mathrm{HF}, \mathrm{HG}, \mathrm{HH}$ & ho & +0.447 & 0 & 0 \\
\hline
\end{tabular}


$\left[\mathrm{H}_{2} \text { TPPc }\right]^{4-}$

\begin{tabular}{|c|c|c|c|c|}
\hline Atom & Atom type & q/e & $\varepsilon / \mathrm{kcal} \mathrm{mol}^{-1}$ & $\sigma / A$ \\
\hline $\begin{array}{l}\text { C1A, C1B, C1C, } \\
\text { C1D, } \\
\text { C4A, C4B, } \\
\text { C4C,C4D }\end{array}$ & ca & +0.0417 & 0.086 & 3.40 \\
\hline $\begin{array}{l}\mathrm{C} 2 \mathrm{~A}, \mathrm{C} 2 \mathrm{~B}, \mathrm{C} 2 \mathrm{C}, \\
\mathrm{C} 2 \mathrm{D}, \\
\mathrm{C} 3 \mathrm{~A}, \mathrm{C} 3 \mathrm{~B}, \mathrm{C} 3 \mathrm{C}, \\
\mathrm{C} 3 \mathrm{D}\end{array}$ & ca & -0.0364 & 0.086 & 3.40 \\
\hline $\begin{array}{l}\mathrm{H} 2 \mathrm{~A}, \mathrm{H} 2 \mathrm{~B}, \mathrm{H} 2 \mathrm{C}, \\
\mathrm{H} 2 \mathrm{D}, \\
\text { H3A, H3B, H3C, } \\
\text { H3D }\end{array}$ & ha & +0.0639 & 0.015 & 2.60 \\
\hline $\mathrm{NA}, \mathrm{NC}$ & $\mathrm{nc}$ & -0.355 & 0.170 & 3.25 \\
\hline $\mathrm{HA}, \mathrm{HC}$ & $\mathrm{hn}$ & +0.166 & 0.016 & 1.069 \\
\hline $\mathrm{NB}, \mathrm{ND}$ & nd & -0.247 & 0.170 & 3.25 \\
\hline $\begin{array}{l}\text { CHA, CHB, } \\
\text { CHC, CHD }\end{array}$ & $\mathrm{cg}$ & +0.151 & 0.086 & 3.40 \\
\hline $\begin{array}{l}\text { C1E, C1F, C1G, } \\
\text { C1H }\end{array}$ & $\mathrm{ca}$ & -0.162 & 0.086 & 3.40 \\
\hline $\begin{array}{l}\text { C2E, C2F, C2G, } \\
\text { C2H, C6E, C6F, } \\
\text { C6G, C6H }\end{array}$ & ca & -0.166 & 0.086 & 3.40 \\
\hline $\begin{array}{l}\mathrm{H} 2 \mathrm{E}, \mathrm{H} 2 \mathrm{~F}, \mathrm{H} 2 \mathrm{G}, \\
\mathrm{H} 2 \mathrm{H}, \mathrm{H} 6 \mathrm{E}, \mathrm{H} 6 \mathrm{~F}, \\
\text { H6G, H6H }\end{array}$ & ha & +0.101 & 0.015 & 2.60 \\
\hline $\begin{array}{l}\mathrm{C} 3 \mathrm{E}, \mathrm{C} 3 \mathrm{~F}, \mathrm{C} 3 \mathrm{G} \\
\mathrm{C} 3 \mathrm{H}, \mathrm{C} 5 \mathrm{E}, \mathrm{C} 5 \mathrm{~F}, \\
\mathrm{C} 5 \mathrm{G}, \mathrm{C} 5 \mathrm{H}\end{array}$ & $\mathrm{ca}$ & -0.109 & 0.086 & 3.40 \\
\hline $\begin{array}{l}\text { H3E, H3F, H3G, } \\
\text { H3H, H5E, H5F, } \\
\text { H5G, H5H }\end{array}$ & ha & +0.148 & 0.015 & 2.60 \\
\hline $\begin{array}{l}\text { C4E, C4F, C4G, } \\
\text { C4H }\end{array}$ & $\mathrm{ca}$ & -0.124 & 0.086 & 3.40 \\
\hline $\begin{array}{l}\text { C7E, C7F, C7G, } \\
\text { C7H }\end{array}$ & $\mathrm{c}$ & +0.906 & 0.086 & 3.40 \\
\hline $\begin{array}{l}\mathrm{O} 1 \mathrm{E}, \mathrm{O} 1 \mathrm{~F}, \mathrm{O} 1 \mathrm{G}, \\
\mathrm{O} 1 \mathrm{H}, \\
\mathrm{O} 2 \mathrm{E}, \mathrm{O} 2 \mathrm{~F}, \mathrm{O} 2 \mathrm{G}, \\
\mathrm{O} 2 \mathrm{H}\end{array}$ & 0 & -0.834 & 0.210 & 2.96 \\
\hline
\end{tabular}


$\mathbf{H}_{4}\left[\mathrm{H}_{2}\right.$ TPPc $]$

\begin{tabular}{|c|c|c|c|c|}
\hline Atom & Atom type & $\mathbf{q} / \mathbf{e}$ & $\varepsilon / \mathrm{kcal} \mathrm{mol}^{-1}$ & $\sigma / A$ \\
\hline $\begin{array}{l}\mathrm{C} 1 \mathrm{~A}, \mathrm{C} 1 \mathrm{~B}, \mathrm{C} 1 \mathrm{C}, \\
\mathrm{C} 1 \mathrm{D}, \\
\text { C4A, C4B, } \\
\text { C4C,C4D }\end{array}$ & $\mathrm{ca}$ & +0.0417 & 0.086 & 3.40 \\
\hline $\begin{array}{l}\mathrm{C} 2 \mathrm{~A}, \mathrm{C} 2 \mathrm{~B}, \mathrm{C} 2 \mathrm{C}, \\
\mathrm{C} 2 \mathrm{D}, \\
\mathrm{C} 3 \mathrm{~A}, \mathrm{C} 3 \mathrm{~B}, \mathrm{C} 3 \mathrm{C}, \\
\mathrm{C} 3 \mathrm{D}\end{array}$ & ca & -0.0364 & 0.086 & 3.40 \\
\hline $\begin{array}{l}\mathrm{H} 2 \mathrm{~A}, \mathrm{H} 2 \mathrm{~B}, \mathrm{H} 2 \mathrm{C}, \\
\mathrm{H} 2 \mathrm{D}, \\
\mathrm{H} 3 \mathrm{~A}, \mathrm{H} 3 \mathrm{~B}, \mathrm{H} 3 \mathrm{C}, \\
\mathrm{H} 3 \mathrm{D}\end{array}$ & ha & +0.0639 & 0.015 & 2.60 \\
\hline $\mathrm{NA}, \mathrm{NC}$ & $\mathrm{nc}$ & -0.355 & 0.170 & 3.25 \\
\hline $\mathrm{HA}, \mathrm{HC}$ & $\mathrm{hn}$ & +0.166 & 0.016 & 1.069 \\
\hline $\mathrm{NB}, \mathrm{ND}$ & nd & -0.247 & 0.170 & 3.25 \\
\hline $\begin{array}{l}\text { CHA, CHB, } \\
\text { CHC, CHD }\end{array}$ & $\mathrm{cg}$ & +0.151 & 0.086 & 3.40 \\
\hline $\begin{array}{l}\mathrm{C} 1 \mathrm{E}, \mathrm{C} 1 \mathrm{~F}, \mathrm{C} 1 \mathrm{G}, \\
\mathrm{C} 1 \mathrm{H}\end{array}$ & ca & -0.094 & 0.086 & 3.40 \\
\hline $\begin{array}{l}\text { C2E, C2F, C2G, } \\
\text { C2H, C6E, C6F, } \\
\text { C6G, C6H }\end{array}$ & $\mathrm{ca}$ & -0.148 & 0.086 & 3.40 \\
\hline $\begin{array}{l}\mathrm{H} 2 \mathrm{E}, \mathrm{H} 2 \mathrm{~F}, \mathrm{H} 2 \mathrm{G}, \\
\mathrm{H} 2 \mathrm{H}, \mathrm{H} 6 \mathrm{E}, \mathrm{H} 6 \mathrm{~F}, \\
\mathrm{H} 6 \mathrm{G}, \mathrm{H} 6 \mathrm{H}\end{array}$ & ha & +0.141 & 0.015 & 2.60 \\
\hline $\begin{array}{l}\mathrm{C} 3 \mathrm{E}, \mathrm{C} 3 \mathrm{~F}, \mathrm{C} 3 \mathrm{G}, \\
\mathrm{C} 3 \mathrm{H}, \mathrm{C} 5 \mathrm{E}, \mathrm{C} 5 \mathrm{~F}, \\
\mathrm{C} 5 \mathrm{G}, \mathrm{C} 5 \mathrm{H}\end{array}$ & ca & -0.069 & 0.086 & 3.40 \\
\hline $\begin{array}{l}\text { H3E, H3F, H3G, } \\
\text { H3H, H5E, H5F, } \\
\text { H5G, H5H }\end{array}$ & ha & +0.157 & 0.015 & 2.60 \\
\hline $\begin{array}{l}\text { C4E, C4F, C4G, } \\
\text { C4H }\end{array}$ & ca & -0.138 & 0.086 & 3.40 \\
\hline $\begin{array}{l}\mathrm{C} 7 \mathrm{E}, \mathrm{C} 7 \mathrm{~F}, \mathrm{C} 7 \mathrm{G}, \\
\mathrm{C} 7 \mathrm{H}\end{array}$ & $\mathrm{c}$ & +0.652 & 0.086 & 3.40 \\
\hline $\begin{array}{l}\text { O1E, O1F, O1G, } \\
\text { O1H }\end{array}$ & o & -0.554 & 0.210 & 2.96 \\
\hline $\begin{array}{l}\mathrm{O} 2 \mathrm{E}, \mathrm{O} 2 \mathrm{~F}, \mathrm{O} 2 \mathrm{G}, \\
\mathrm{O} 2 \mathrm{H}\end{array}$ & oh & -0.608 & 0.210 & 2.96 \\
\hline HE, HF, HG, HH & ho & +0.447 & 0 & 0 \\
\hline
\end{tabular}




\section{Trifluorotoluene}

\begin{tabular}{|c|c|c|c|c|}
\hline Atom & Atom type & $\mathbf{q} / \mathbf{e}$ & $\varepsilon / \mathrm{kcal} \mathrm{mol}^{-1}$ & $\sigma / A$ \\
\hline $\mathrm{C} 1$ & $\mathrm{ca}$ & -0.100 & 0.086 & 3.40 \\
\hline $\mathrm{H} 1$ & ha & +0.139 & 0.015 & 2.60 \\
\hline $\mathrm{C} 2, \mathrm{C} 6$ & $\mathrm{ca}$ & -0.134 & 0.086 & 3.40 \\
\hline $\mathrm{H} 2, \mathrm{H} 6$ & ha & +0.142 & 0.015 & 2.60 \\
\hline $\mathrm{C} 3, \mathrm{C} 5$ & $\mathrm{ca}$ & -0.081 & 0.086 & 3.40 \\
\hline $\mathrm{H} 3, \mathrm{H} 5$ & ha & +0.151 & 0.015 & 2.60 \\
\hline $\mathrm{C} 4$ & $\mathrm{ca}$ & -0.168 & 0.086 & 3.40 \\
\hline $\mathrm{CF}$ & c3 & +0.687 & 0.109 & 3.40 \\
\hline $\mathrm{F} 1, \mathrm{~F} 2, \mathrm{~F} 3$ & $\mathrm{f}$ & -0.238 & 0.061 & 3.118 \\
\hline
\end{tabular}

\section{Bonded parameters}

Bond stretching and bond angle bending parameters for $\mathrm{ZN}$ atoms listed below. Other force field parameters are taken from the Generalized Amber Force Field.

\begin{tabular}{|l|l|ll|}
\hline \multicolumn{1}{|c|}{ Bond } & $\mathbf{c} / \mathbf{k c a l ~ m o l}^{-1} \mathbf{A}^{-2}$ & \multicolumn{2}{c|}{$\mathbf{r}_{\mathbf{0}} / \mathbf{A}$} \\
\hline ZN-nc & 56 & 2.07 & \\
\hline ZN-nd & 56 & 2.07 & \\
\hline
\end{tabular}

\begin{tabular}{|l|l|l|}
\hline \multicolumn{1}{|c|}{ Angle } & \multicolumn{1}{|c|}{$\mathbf{k} / \mathbf{k c a l ~ m o l}^{-2}$ rad $^{-2}$} & \multicolumn{1}{c|}{$\boldsymbol{\theta}_{\mathbf{0}} /$ degrees } \\
\hline nc-ZN-nc & 31.1 & 180.0 \\
\hline nc-ZN-nd & 31.1 & 90.0 \\
\hline nd-ZN-nd & 31.1 & 180.0 \\
\hline ca-nc-ZN & 47.65 & 126.5 \\
\hline ca-nd-ZN & 47.65 & 126.5 \\
\hline
\end{tabular}

Sample input files are available on request from the authors. For each simulated system (water-TFT interface with 1,16 , and 32 porphyrin molecules, each porphyrin dimer in water) a lammps input script and data file is included, along with parameter file containing GAFF parameters. 
Photocurrent transient measurements. Photocurrent measurements using a DC illumination were performed in a specialised 4-electrode electrochemical cell, using the light emitting diode (LED) driver provided by Metrohm Autolab in conjunction with a PGSTAT204 in the configuration presented in Supplementary Fig. 11. The reference electrodes used were $\mathrm{Ag} / \mathrm{AgCl}$ for the organic reference solution and $\mathrm{Ag} / \mathrm{AgCitrate}$ for the aqueous electrolyte. The counter electrodes in each phase were Pt. The light source was a trifocal LED with a beam width of $18^{\circ}$ and $\lambda_{\max }$ of $470 \mathrm{~nm}$. The emission spectrum of the LED, as well as the absorption spectra of ZnTPPc, $\mathrm{H}_{2}$ TPPc and their respective Por-INs are presented in Supplementary Fig. 12. As clearly illustrated in Supplementary Fig. 12, a major advantage of porphyrin nanostructure formation is the broadening of the absorption spectrum, a highly desirable trait when designing nanomaterials for use in solar energy conversion. ${ }^{31}$ The broadening of the absorption spectra for ZnPor-INs and $\mathrm{H}_{2}$ Por-INs leads to a far greater overlap with the emission spectrum of the $470 \mathrm{~nm}$ LED in comparison to the aqueous solutions of $\mathrm{ZnTPPc}$ and $\mathrm{H}_{2} \mathrm{TPP}$.
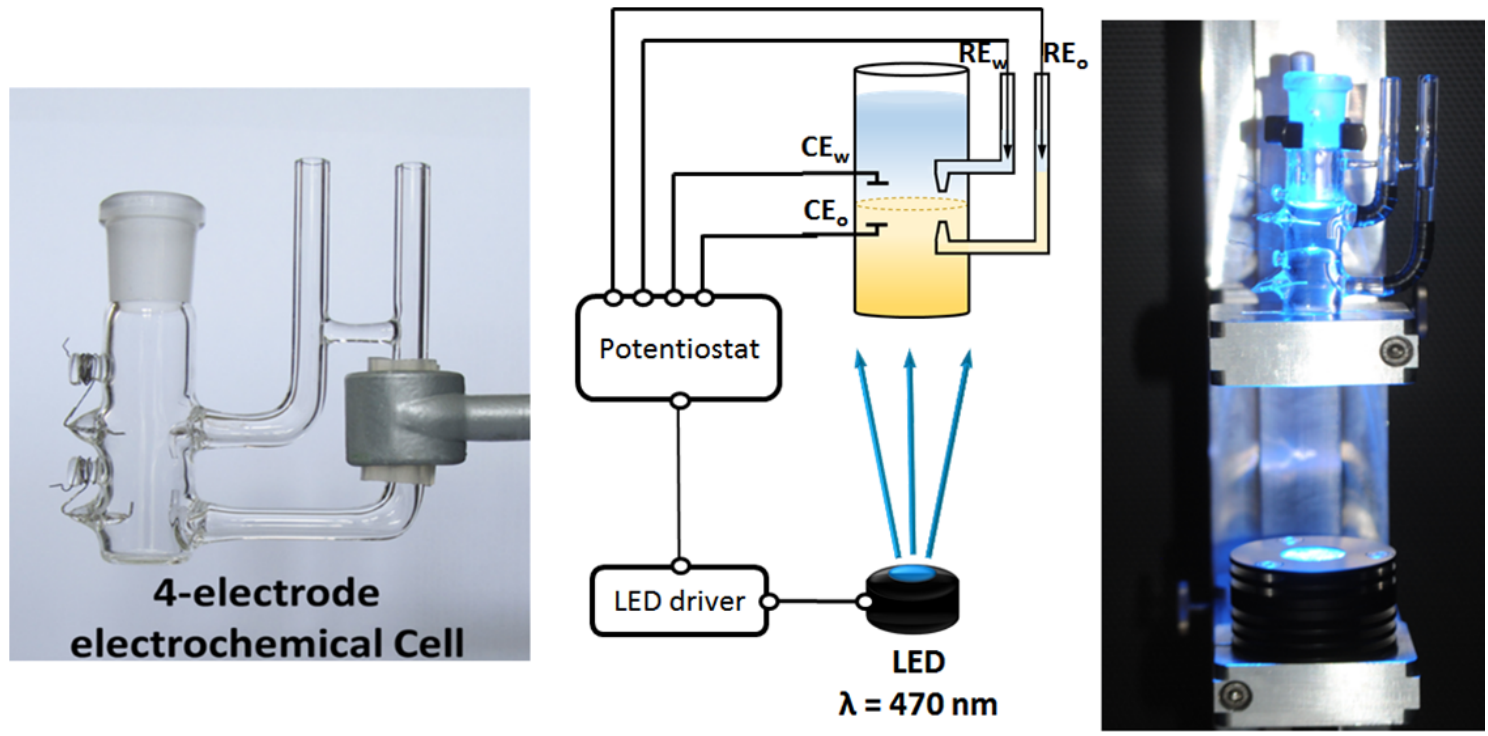

Supplementary Fig. 11 | Image of the 4-electrode electrochemical cell, with a schematic and image of the setup used for photocurrent transient measurements. $\left(\mathrm{CE}_{\mathrm{w}}\right.$ and $\mathrm{CE}_{\mathrm{o}}$ are the counter electrodes in the water and TFT phases, respectively, and $\mathrm{RE}_{\mathrm{w}}$ and $\mathrm{RE}_{\mathrm{o}}$ are the reference electrodes in each phase).
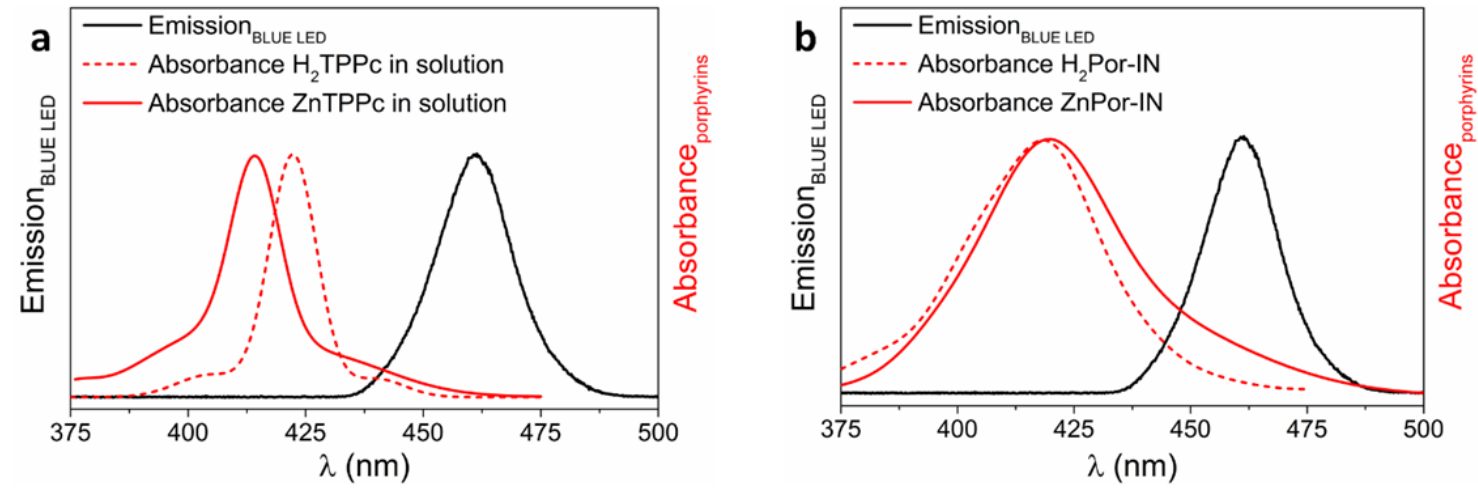

Supplementary Fig. 12 | Overlaps between the emission of the blue LED and absorption of a, ZnTPPc and $\mathrm{H}_{2}$ TPPc in solution and $\mathbf{b}$, their respective Por-INs. 
The light intensity of the LED was controlled through the LED driver presented in Supplementary Fig. 11. This driver is a current source that converts an input voltage difference signal provided by the potentiostat to a current output signal directed to the LED. This conversion is performed using the Digital to Analog converter (DAC164) according to:

$$
i_{\mathrm{LED}}=\left(\frac{i_{\text {range }}}{\mathrm{V}_{\text {range }}}\right) \mathrm{V}_{\mathrm{DAC} 164}=\left(\frac{1000 \mathrm{~mA}}{10 \mathrm{~V}}\right) \mathrm{V}_{\mathrm{DAC} 164}=\left(100 \mathrm{~mA} \cdot \mathrm{V}^{-1}\right) \cdot \mathrm{V}_{\mathrm{DAC} 164}
$$

where $i_{\text {LED }}$ is the output driving current. For calculations, in order to convert this current to light intensity $\left(\mathrm{mW} \cdot \mathrm{cm}^{-2}\right.$ ) and photon flux (\# photons $\cdot \mathrm{s}^{-1} \cdot \mathrm{cm}^{-2}$ ), the LED intensity was calibrated using a photodiode located at a controlled distance from the light source. The calibration was performed knowing the responsivity $(\mathrm{R})$ of the photodiode and the area of the electrified liquid-liquid interface using the following relationship:

$$
P\left(\mathrm{~mW} \cdot \mathrm{cm}^{-2}\right)=\frac{j_{\text {photodiode }}(\mathrm{mA})}{\text { Area }\left(\mathrm{cm}^{2}\right) \cdot \mathrm{R}\left(\mathrm{mA} \cdot \mathrm{mW}^{-1}\right)}
$$

The photon flux at each driving current was calculated from the light intensity knowing that the energy of a photon with a wavelength of $470 \mathrm{~nm}$ is $4.226 \times 10^{-19} \mathrm{~J}$. The results of these calculations are presented in Supplementary Fig. 13.
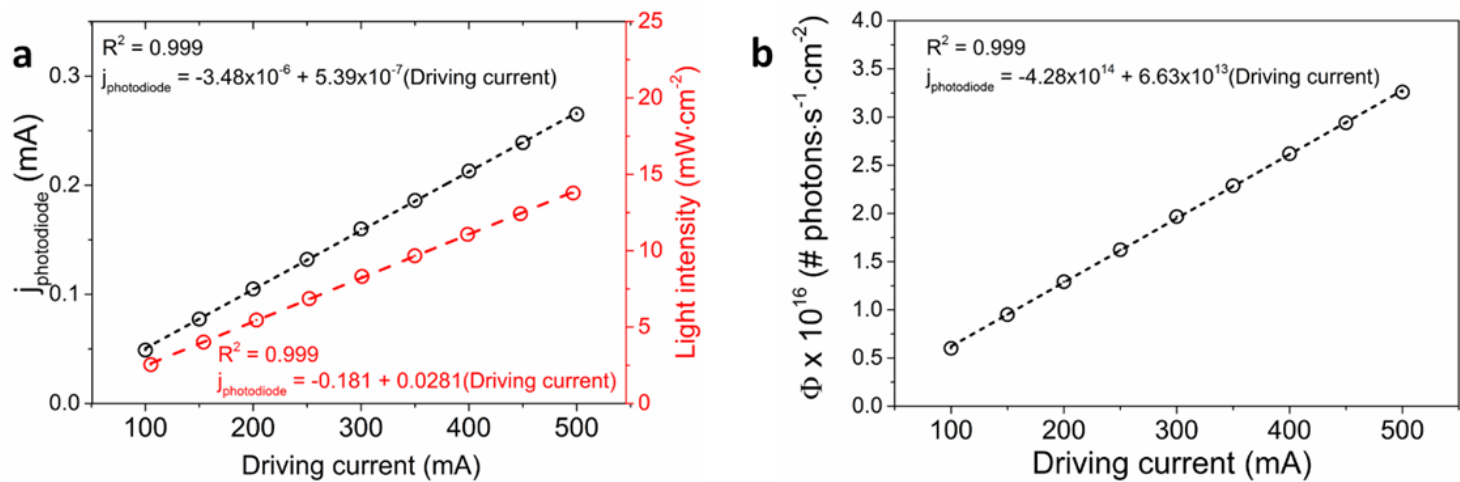

Supplementary Fig. $13 \mid$ a, Photocurrents measured from the calibration photodiode at each driving current applied to the LED driver, and the calculated light intensity provided by the blue LED. b, The calculated photon flux at the electrified liquid-liquid interface at each driving current applied to the LED driver. 


\section{Supplementary References}

1. Pasternack, R. F., Francesconi, L., Raff, D. \& Spiro, E. Aggregation of nickel(II), copper(II), and zinc(II) derivatives of water-soluble porphyrins. Inorg. Chem. 12, 2606-2611 (1973).

2. Nagatani, H., Tanida, H., Harada, M., Asada, M. \& Sagara, T. Polarized totalreflection X-ray absorption fine structure of zinc(II) porphyrin at the heptane-water interface. J. Phys. Chem. C 114, 18583-18587 (2010).

3. Moin, S. T. \& Hofer, T. S. Zinc- and copper-porphyrins in aqueous solution - two similar complexes with strongly contrasting hydration. Mol. BioSyst. 12, 2288-2295 (2016).

4. Nagatani, H., Tanida, H., Ozeki, T. \& Watanabe, I. Zinc(II) porphyrins at the air-water interface as studied by polarized total-reflection X-ray absorption fine structure. Langmuir 22, 209-212 (2006).

5. Tanida, H., Nagatani, H. \& Watanabe, I. Polarized total-reflection X-ray absorption fine structure for self-assembled monolayer of zinc porphyrin at air-water interface. $J$. Chem. Phys. 118, 10369-10371 (2003).

6. Moin, S. T. \& Hofer, T. S. Hydration of porphyrin and Mg-porphyrin: ab initio quantum mechanical charge field molecular dynamics simulations. Mol. BioSyst. 10, 117-127 (2014).

7. Clarke, S. E., Wamser, C. C. \& Bell, H. E. Aqueous complexation equilibria of mesotetrakis(4-carboxyphenyl)porphyrin with viologens: Evidence for 1:1 and 1:2 complexes and induced porphyrin dimerization. J. Phys. Chem. A 106, 3235-3242 (2002).

8. Pasternack, R. F. et al. On the aggregation of meso-substituted water-soluble porphyrins. J. Am. Chem. Soc. 94, 4511-4517 (1972).

9. Krishnamurthy, M., Sutter, J. R. \& Hambright, P. Monomer-dimer equilibration of water -soluble porphyrins as a function of the co-ordinated metal ion. J. Chem. Soc. Chem. Comm. 13-14 (1975).

10. Cordeiro, R. M., Miotto, R. \& Baptista, M. S. Photodynamic efficiency of cationic meso-porphyrins at lipid bilayers: Insights from molecular dynamics simulations. $J$. Phys. Chem. B 116, 14618-14627 (2012).

11. Kalyanasundaram, K. \& Neumannspallart, M. Photophysical and redox properties of water-soluble porphyrins in aqueous-media. J. Phys. Chem. 86, 5163-5169 (1982).

12. Hofstra, U., Koehorst, R. B. M. \& Schaafsma, T. J. Excited-state properties of watersoluble porphyrin dimers. Chem. Phys. Lett. 130, 555-559 (1986).

13. Maiti, N. C., Mazumdar, S. \& Periasamy, N. J- and H-aggregates of porphyrin-surfactant complexes: Time-resolved fluorescence and other spectroscopic studies. J. Phys. Chem. B 102, 1528-1538 (1998).

14. Khairutdinov, R. F. \& Serpone, N. Photoluminescence and transient spectroscopy of free base porphyrin aggregates. J. Phys. Chem. B 103, 761-769 (1999).

15. Castriciano, M. A. et al. Structural features of meso-tetrakis(4carboxyphenyl)porphyrin interacting with amino-terminated poly(propylene oxide). Macromolecules 39, 5489-5496 (2006).

16. Akins, D. L., Ozcelik, S., Zhu, H.-R. \& Guo, C. Fluorescence decay kinetics and structure of aggregated tetrakis(p-sulfonatophenyl)porphyrin. J. Phys. Chem. 100, 14390-14396 (1996).

17. Akins, D. L., Zhu, H. R. \& Guo, C. Absorption and raman scattering by aggregated meso-tetrakis(p-sulfonatophenyl)porphine. J. Phys. Chem. 98, 3612-3618 (1994).

18. Vlčková, B. et al. Surface-enhanced resonance Raman spectra of free base 5,10,15,20- 
tetrakis(4-carboxyphenyl)porphyrin and its silver complex in systems with silver colloid: Direct adsorption in comparison to adsorption via molecular spacer. J. Phys. Chem. 97, 9719-9729 (1993).

19. Yamaguchi, H., Nakano, M. \& Itoh, K. Resonance Raman scattering study of the pcation radicals of magnesium, zinc, and copper tetraphenylporphines. Chenistry Lett. 1397-1400 (1982).

20. Li, X. Y., Czernuszewicz, R. S., Kincaid, J. R., Su, Y. O. \& Spiro, T. G. Consistent porphyrin force field. 1. Normal-mode analysis for nickel porphine and nickel tetraphenylporphine from resonance Raman and infrared spectra and isotope shifts. $J$. Phys. Chem. 94, 31-47 (1990).

21. Li, X. Y., Czernuszewicz, R. S., Spiro, T. G. \& Kincaid, J. R. Consistent porphyrin force field. 3. Out-of-plane modes in the resonance Raman spectra of planar and ruffled nickel octaethylporphyrin. J. Am. Chem. Soc. 111, 7012-7023 (1989).

22. Wang, J. M., Wolf, R. M., Caldwell, J. W., Kollman, P. A. \& Case, D. A. Development and testing of a general amber force field. J. Comput. Chem. 25, $1157-$ 1174 (2004).

23. Peters, M. B. et al. Structural aurvey of zinc containing proteins and the development of the Zinc AMBER Force Field (ZAFF). J. Chem. Theory Comput. 6, 2935-2947 (2010).

24. Jakalian, A., Jack, D. B. \& Bayly, C. I. Fast, efficient generation of high-quality atomic charges. AM1-BCC model: II. Parameterization and validation. J. Comput. Chem. 23, 1623-1641 (2002).

25. Jakalian, A., Bush, B. L., Jack, D. B. \& Bayly, C. I. Fast, efficient generation of highquality atomic charges. AM1-BCC Model: I. Method. J. Comput. Chem. 21, 132-146 (2000).

26. Lin, F. \& Wang, R. Systematic derivation of AMBER force field parameters applicable to zinc-containing systems. J. Chem. Theory Comput. 6, 1852-1870 (2010).

27. Martyna, G. J., Tobias, D. J. \& Klein, M. L. Constant pressure molecular dynamics algorithms. J. Chem. Phys. 101, 4177-4189 (1994).

28. Darden, T., York, D. \& Pedersen, L. Particle mesh Ewald: An N· $\log (\mathrm{N})$ method for Ewald sums in large systems. J. Chem. Phys. 98, 10089-10092 (1993).

29. Darve, E. \& Pohorille, A. Calculating free energies using average force. J. Chem. Phys. 115, 9169-9183 (2001).

30. Fiorin, G., Klein, M. L. \& Hénin, J. Using collective variables to drive molecular dynamics simulations. Mol. Phys. 111, 3345-3362 (2013).

31. McHale, J. L. Hierarchal light-harvesting aggregates and their potential for solar energy applications. J. Phys. Chem. Lett. 3, 587-597 (2012). 
